\title{
Totenabbilder bei den Chanten und Mansen
}

Der Brauch der Chanten und Mansen, nach dem Ableben eines Menschen eine Darstellung des Toten (in der deutschsprachigen Fachliteratur bekannt als Effigies oder imagines mortis) anzufertigen und eine bestimmte Zeit im Hause aufzubewahren, wurde in der ethnographischen Literatur des öfteren behandelt (Andrejew 1832; Bartenjew 1895; Beketow 1857; Beljawski 1833; Wyssozki 1908; Georgi 1776; Gondatti 1888; Sujew 1947; Kannisto 1958; Karjalainen 1921; Kowalski 1853; Nowizki 1884; Pallas 1778; Patkanow 1897; Podrewski 1895; Prytkowa 1971; Rosljakow 1896; Rudenko 1972; Starzew 1928; Finsch und Brem 1882; Schawrow 1871; Schuchow 1914; Eirie 1839). Unter den in den letzten beiden Jahrzehnten herausgegebenen Arbeiten sind die Artikel und Arbeiten von W. N. Tschernezow (1959, 1964 und 1971) von Interesse, weiterhin eine kurze Zusammenstellung von Materialien über diese Erscheinung mit einer Analyse der Totenabbilder, die in Museen aufbewahrt werden, in der Arbeit von S. W. Iwanow (1970) und die Artikel von B. P. Schischlo (1972, 1975). In einigen von mir verfassten Artikeln (1971, 1972, 1974, 1975 a, b, c, 1976 a, b, 1978, 1980 u. a.) werden ebenfalls Materialien zu dieser Frage angeführt. Das Ziel der vorliegenden Arbeit ist es, die Abbildungsform der Toten aufgrund der von mir aufgefundenen Materialien, der Archivsammlungen der Museen und der Literaturangaben zu untersuchen.

Das Totenabbild ist sozusagen die Behausung einer der Seelen des Menschen und zwar der Reinkarnations- oder der vierten Seele, die nach der Klassifikation von W. N. Tschernezow lili genannt und mit der Atmung (Tschernezow 1959, 137-138) ${ }^{1}$ assoziiert wird. Ihr Aufenthaltsort ist meist das Haupt, die Haare. Gerade deshalb wird wahrscheinlich das Toten- 
abbild oftmals sonat, క̌onat, der Schädel, genannt und am Kopf des Totenabbildes werden die Haare des Toten befestigt. Weiterhin bestätigen uns in diesen Gedanken auch die Aufbewahrungsfristen der Totenabbilder im Haus, die 4 - 5 Jahre ${ }^{2}$ betragen. Innerhalb dieser Zeitspanne kann die reinkarnierende Seele im Neugeborenen wieder aufleben (Tschernezow 1970, 18). Zu erwähnen ist ferner, dass dem Totenabbild eine vollständige Bekleidung beigefügt wurde, d. h. einige Hemden oder Kleider, ein Umhang namens Chalat (für das weibliche Abbild), ein Tuchkaftan oder Gus (= geschlossene Hemdjacke), eine Pelz-Maliza (= Hemdjacke), ein Sowik ( = durchgehend geschlossener Pelzmantel) ${ }^{3}$ oder ein Pelzmantel.

Sehr oft besitzt das Totenbild keinen festen Fuss. So sieht zum Beispiel das Abbild der toten Frau unseres Informanten aus dem Ort Owolyngort am Fluss Synja aus (Sokolowa 1976 b, 401, Abb. 10). Nur aus der Bekleidung wurde auch das Abbild des toten Alten Murkin aus der Rentierzüchtersiedlung Chorjer am Fluss Synja (Sokolowa 1974, 51-52; Sokolowa 1976 b, 399) hergestellt. In solchen Fällen wird der Fuss des Abbildes aus Kleidern, Hemden oder kleinen Kaftanen gebildet, die aufeinander gezogen oder ineinander eingesetzt werden. Ein solches Abbild einer toten Frau wurde von mir unter anderen Totenabbildern in einer Truhe in einem verlassenen Haus entdeckt, das sich im Ort Nimwoschgort an der Synja befand (Abb. 1). Hier wurden ein kleines himbeerfarbenes Kattunkleid und ein hellbrauner offener Tuchkaftan mit Bändern verschnürt und ineinander gelegt. Zwei weitere Kaftane aus gelbem Tuch und mit Armeln und Kragen versehen, ebenso wie mit Bändern aus schwarzem Tuch, waren eckförmig zueinander ausgerichtet und in das erste Kleiderbündel eingelegt (Abb. 2). Die Ecke eines Kaftans

1 Aber nicht Seele = Schatten, is, is-xor oder iles (Iwanow 1970, S. 38).

2 In Wirklichkeit sind es nach einer besonderen ritualen Berechnung (möglicherweise in Verbindung mit der Vorstellung von zwei für die Frauen und drei für die Männer existierenden Reinkarnationen - Tschernezow 1959, 139, Anmerkung 79) 2 bis 3 Jahre (Sokolowa 1974, 50, Anmerkung 1).

3 Gus, Maliza und Sowik sind geschlossene, vorn nicht ausgeschnittene Bekleidungsstücke, die Maliza mit dem Pelz nach innen, Gus und Sowik mit dem Pelz nach aussen; ein Gus wurde auch aus Stoff angefertigt. 
hing aus dem Kleiderbündel heraus und deutete den Kopf an. Darüber waren noch zwei schwarze Tuchkaftan-Chalate vom Typ der Frauenkleidung həj-säx angezogen. Die Masse des Abbildes betragen $25 \times 13 \mathrm{~cm}$ (Sokolowa 1974, 53; Sokolowa 1976 b, 402).

Am Rand des Dorfes Lopchari bei der Mündung des Flusses Kunowat (rechter Zufluss des Ob) fand ich 1973 einen kleinen (Länge $20 \mathrm{~cm}$ ) Frauenpelzmantel (Abb. 3), offensichtlich das Abbild einer toten Frau, das nach Ablauf der Frist der Aufbewahrung im Haus im Wald weggeworfen worden war. Es ist möglich, dass ein ähnliches Abbild einer toten Frau auf dem Dachboden eines alten verfallenen Hauses in der verlassenen Siedlung Schischingi am Ob aufbewahrt wurde. Leider war alles, was auf dem Boden aufbewahrt wurde, schon nicht mehr unberührt. Deshalb ist nicht ganz klar, ob die kleinen Bekleidungsstücke, die übereinander gezogen waren, den Rest eines Totenabbildes darstellen: Es ist möglich, dass es dem Fund einer metallischen Froschdarstellung (Sokolowa 1975 a) zuzuordnen ist.

In der Siedlung Schischingi wurde das Abbild einer toten Frau gefunden, das ebenso aus Kleidungsstücken zusammengesetzt war (Abb. 4) (Sokolowa 1974, 54; Sokolowa 1976 b, 403). Aber ihr Gesicht wurde durch eine Münze imitiert (Abb. 5). Im Dorf Lopchari war das Abbild des toten Alten Jarkin ebenfalls aus klein bemessenen Kleidungsstücken hergestellt, während das Gesicht durch eine flachgedrückte Münze dargestellt war (Sokolowa 1976 b, 400).

Eines von drei Totenabbildern, die ich 1973 auf dem Dachboden eines alten Hauses in der Siedlung Schischingi gefunden hatte, war aus kleinen Kleidungsstücken angefertigt und der Kopf bestand aus zwei zusammengefalteten Bleistückchen (Abb. $5 \mathrm{~h}$ ). Der Kopf war in ein Stückchen Stoff eingeschlagen, das ein Kopftuch darstellt. Die Bekleidung besteht aus zwei Kleiderhemden, die übereinandergezogen wurden und aus orangenem und gestreiftem Stoff bestanden (Grösse $23 \times 14 \mathrm{~cm}$ ). Daneben lag ein kleines Oberbekleidungsstück, ein Pelz-Sach (= Frauenmantel), eine Maliza mit einer Kapuze und einem Malizahemd aus blauem Stoff. Der Pelz-Sach ist zweischichtig, mit dem Pelz nach innen und aussen und mit Applikationsstreifen aus hellorangenem Stoff. Er weist zwei Paar Bänder aus hellem Stoff auf. Hinten sind am Kragen Glasperlen auf zwei Fäden aufgereiht. Die Grösse beträgt $19 \times 12 \mathrm{~cm}$. Saum und Ränder des Malizahemdes sind mit 
rotem Stoff besetzt. Um den Kragen ist ein schmales Band gebunden, dessen Enden auf den Rücken fallen. Der Gürtel über dem Malizahemd besteht aus orangefarbenem Baumwollstoff, aus dem gleichen wie auch eines der Hemden des Totenabbildes (sicherlich gehörten Maliza und Malizahemd zu diesem Totenabbild). Der Gürtel hat einen angebundenen Kupferring, ein Gürtelende ist abgeschnitten, womöglich zusammen mit der Münze, die normalerweise die Angehörigen des Toten an der Bekleidung einer solchen Seelenbehausung anbanden. Die Grösse dieser Bekleidung beträgt $20,5 \times 13,5 \mathrm{~cm}$. Dieses Totenabbild wurde mit zwei anderen und dazugehörigen Geschenkdarbringungen gefunden (Sokolowa 1976 a, 1982; Sokolowa 1982, s. Farbfotos).

Drei von mir gefundene Totenabbilder hatten einen Holzfuss. Das ist einmal offensichtlich das Totenabbild einer Frau (die Oberbekleidung aus Pelz ist vermodert, und die Kleider und Hemden der männlichen und weiblichen Abbilder haben den gleichen Schnitt) aus einem alten verfallenen Haus der Siedlung Owolyngort (Sokolowa 1974, 52). Die Stütze bildete eine Büste (6x $2 \mathrm{~cm}$ ) mit geschnitzten Gesichtszügen (Abb. 5 b). Zweitens gehören hierher zwei oder drei Abbilder, die ich im Jahre 1973 auf dem Dachboden eines alten Hauses der Siedlung Schischingi fand, in dem früher die Chanten Litwa gewohnt haben. Die Füsse für diese Abbilder wurden ebenfalls von Holzbüsten gebildet; anstelle des Gesichts waren Münzen angebracht (Abb. $5 \mathrm{c}$ ). Das männliche Abbild unterschied sich etwas von dem weiblichen: Die das Gesicht darstellende Münze war in den ausgehöhlten Holzgrund des Kopfes eingebracht. Das Abbild des verstorbenen Mannes war in zwei Hemden aus buntem Kattun und braunem Stoff und in eine Maliza mit Kapuze aus braunem Rentierfell mit einem schwarzen Malizahemd gekleidet. Das Malizahemd ist am Saum und am Kragenrand mit rotem Stoff besetzt. Der Gürtel über dem Malizahemd besteht aus gekauftem schmalen Band, so auch das Band am Hals des anderen Totenabbildes, von dem ich bereits berichtete. Von hinten ist am Gürtel ein Kupferring befestigt. Die Masse des Abbildes betragen $20 \times 14,5 \mathrm{~cm}$, die von dessen Fuss $10 \times 6 \mathrm{~cm}$. Beim Frauenabbild sind Kopf und Gesicht flach, eine Münze ist auf das Gesicht gelegt und darüber ist Mull gewickelt (Abb. 5 c). Die Masse des Abbildes belaufen sich auf $13 \times 6 \mathrm{~cm}$, die von dessen Fuss auf $6 \times 3 \mathrm{~cm}$. Die Bekleidung besteht aus zwei Kleidern, die aufeinandergezogen sind. Darüber ist ein offener PelzSach aus braunem Rentierfell gezogen, d. h. über die Kleider aus buntem 
Kattun und brauner Wolle; das Ganze ist mit zwei Paar Bändern zu verschnüren. Der Gürtel ist ein rosa Band, die Bänder sind aus grobem Wildleder. Am Ende des Gürtels ist eine 15-Kopekenmünze aus dem Jahre 1946 angebunden. Zusammen mit diesen Abbildern lagen auf dem Boden: vier kleine Votivkopftücher, Kleidung (Sowik, zwei Chalate), sowie sechs grosse Kopftücher, elf Stoffteile und ein Tierfell. Der Sowik aus weissem Rentierfell hatte ebensolche Masse wie auch die Abbilder der Toten. Ebenso gross war der Chalat aus schwarzem Kattun, der am Saum und in der Mitte mit rosa Kattun besetzt war. Im Ármel waren zwei Münzen zu 2 und 5 Kopeken aus dem Jahre 1905 eingebunden. Zweimal so gross war der Baumwollchalat mit der spitzen Kapuze, den langen Armeln und den Bändern. Noch grösser war ein anderer Chalat (bis $50 \mathrm{~cm}$ Länge) aus schwarzem Tuch mit einem breiten Kragen. Die kleinen Votiv- und die gewöhnlichen Tücher waren aus bunten Kattunteilen genäht und wiesen zusätzlich aufgesetzte Zierbänder anderer Farbe mit selbstgemachten Fransen auf. In der Ecke eines der gekauften Tücher war eine 15-Kopekenmüntze aus dem Jahre 1932 eingewickelt. In den Ecken der Kattunstücke waren 10-, 15- und 20-Kopekenmünzen aus den Jahren 1902, 1932, 1933, 1936, 1941 und 1945 eingewickelt. Auf den Tüchern und Stoffteilen sind Blutspuren von Opfertieren zu finden (Sokolowa 1982, s. Farbfotos).

Vier Totenabbilder hatten einen Metallfuss. Das sind zwei Abbilder aus der Siedlung Gorbungort, eines aus der Siedlung Wytwoschgort und eines aus der Siedlung Nimwoschgort an der Synja. Den Fuss der Gorbungorter Abbilder eines toten Mannes und einer toten Frau bildeten Bleifiguren, von denen der eine zooanthropomorph war (Abb. 5 f). Das Mass dieser Figur betrug ca. $6 \mathrm{~cm}$. Das Abbild des toten Mannes war anthropomorph, es war in Männerkleidung gehüllt (Maliza), die jedoch vermodert war (Abb. 6); das Frauenabbild war in einen Pelz-Sach gehüllt (Abb. 7) (Sokolowa 1974, 52-53; Sokolowa 1976 b, 400-401). Das Mass des Abbildes in der Kleidung betrug 16 x $9 \mathrm{~cm}$. Die Grösse des aus Nimwoschgortsk stammenden Abbildes des toten Mannes betrug $22,5 \times 12 \mathrm{~cm}$, die anthropomorphe Metallfigur war $9 \mathrm{~cm}$ lang. An dieser sind die Gesichtszüge angedeutet (Abb. $5 \mathrm{~d}$ ). Die Seelenbehausung bestand aus zwei Hemden, die ausserdem noch in eine Maliza aus Rentierfell, einen hellen Tuch-Sowik, ein Malizahemd, einen Tuch-Sowik und ein Malizahemd mit Gürtel (Sokolowa 1974, 53; Sokolowa 1976 b, 401-402) ge- 
hüllt sind. Das aus Wytwoschgorotsk stammende Abbild des toten Mannes ist kleiner, die Grösse der Metallfigur beträgt $4,5 \mathrm{~cm}$, die Arme sind ebenfalls angedeutet (Abb. $5 \mathrm{~g}$ ). Die Masse mit der Bekleidung betragen (Abb. 8) 20,5 $x 11,5 \mathrm{~cm}$. Zusammen mit der Abbildung des toten Mannes in der Truhe wurden Geschenke für ihn aufbewahrt ( 6 speziell aus hellem Rentierfell angefertigte kleine Sowik, 6 gleichartige offene Pelz-Sach, 6 Votiv-Kattunkopftücher, ein Bündel aus zwei Kopftüchern und ein Tierfell mit einer Münze aus dem Jahre 1935, ebenso wie eine Holznadel und eine Schablone zum Netzeknüpfen), s. Abb. 9 (Sokolowa 1974, 52-53; Sokolowa 1976 b, 402-403).

Es ist möglich, dass das Totenabbild eine Froschfigur war, die von mir in der Siedlung Schischingi im Haus der Pusylanows gefunden wurde, das verlassen war und verfiel. Es ist offensichtlich in der Truhe, die in den Ruinen des Hausdaches gefunden wurde, erhalten geblieben. Daneben lagen Kleidungsstücke und Opfertücher mit Münzen aus den Jahren 1893 und 1903. Die Figur des $6 \mathrm{~cm}$ langen Frosches selbst war in ein Tuch eingewickelt, aber nicht mit Kleidern oder Hemden versehen, wie die Totenabbilder. Wie wir jedoch weiterhin sehen werden, wird manchmal auch die Seelenbehausung in Stoffflicken eingeschlagen. Die zoomorphe totemistische Abstammung der Totenabbilder war für die Obugrier charakteristisch (Tschernezow 1971, 30; Sokolowa 1975 b, 149-152). Die kieine Bekleidung, die für die Totenabbilder charakteristisch ist, wurde auch hier gefunden, wo die Froschfigur entdeckt wurde (Sokolowa 1975 b, 146-147, Abb. 2, 3).

In einem anderen, von der Zeit nicht unberührt gebliebenem Haus der Siedlung Schischingi fand ich im Jahre 1973 ein weiteres Totenabbild. Es wurde in einer runden Schachtel aus Birkenrinde aufbewahrt, die in ein gelbes Wolltuch eingeschlagen war. Das Totenabbild wies einen Bleifuss auf, eine Büste von $4 \times 2,5 \mathrm{~cm}$, an der Stelle des Gesichtes war eine 10-Kopekenmünze aus dem Jahre 1923 aufgelegt (Abb. 5 e). Bekleidet war es mit Wintersachen mit einer Kapuze (Maliza?), die vermoderte. Zusammen mit dieser Seelenbehausung befanden sich dort ein Glasohrring, ein Kinderspielzeug (Holzdose) und eine runde Metallbüchse mit darin liegenden kleinen Flicken.

Die Totenabbilder an den Flüssen Synja und Kunowat hiessen ittarma.

Nach dem tragischen, auf irgendeine Weise unnatürlich erfolgten Tod eines Menschen wurden zwei Totenabbilder angefertigt: ein gewöhnliches, 
ittarma, und ein besonderes, das ura genannt wurde. Diese Abbilder waren grösser, bis zu $40 \mathrm{~cm}$ gross und hatten keinen Fuss. Sie wurden aus Kleidungsstücken angefertigt, s. Abb. 10. Solche Abbilder wurden nicht zu Hause aufbewahrt, sondern in besonderen Grabhäuschen an einer speziellen Kultstätte: Ura. Solche Kultstätten und Totenabbilder (Ertrunkene) wurden erstmals von mir entdeckt (Sokolowa 1974, 54-59, 1976 a, Abb.; Sokolowa 1976 b, 406-411, Abb. 11, 12, 1977, Abb. 2, 3 b, 1982 s. Farbfotos). Wie wir weiterhin sehen werden, ist es jedoch möglich, dass ähnliche Abbilder tragisch ums Leben gekommener Menschen schon früher von Forschern angetroffen, von diesen aber als übliche Abbilder angesehen wurden.

Von noch grösserer Vielfalt der Form der Totenabbilder bei den Chanten und Mansen zeugen Exponate in Museen.

Totenabbilder, die aus einem Bekleidungsstück angefertigt sind, werden im Museum für Anthropologie und Ethnographie (MAE), im Staatlichen Museum für Ethnographie der Völker der UdSSR (SME) in Leningrad, im Tobolsker Heimatkundemuseum und im Nationalmuseum in Helsinki (Suomen Kansallismuseo - SKM) aufbewahrt. Im Tobolsker Museum werden neben Kinderspielzeugpuppen ungefähr 10 Totenabbilder von den Flüssen Sewernaja Soswa, Kazym und Ob aufbewahrt (Bestände des Tobolsker Museums U1602, U1603, U1605, U1627, U1638, U1639, U1645, U1647, U1648, U1651). Im Unterschied zu Kinderspielzeugpuppen besitzen diese keinen Kopf (bei den Kinderpuppen sind die Köpfe aus einem Entenschnabel angefertigt worden). In der Inventarliste sind sie akan oder akan-pox genannt (akan 'Puppe', pox 'Junge'). Sie sind alle aus kleinen Bekleidungsstücken angefertigt worden, aus einer Maliza oder einem offenen Pelz-Sach (abhängig vom Geschlecht des Verstorbenen), oder aus Hemdkleidern aus Kattun. Die Kleidung ist mit Blechschildchen, mit bunten Tuchstreifen und Stoffapplikationen verziert. Aus Tuch sind auch Zöpfe imitiert. Bei einem Totenabbild (U1605) bilden kleine Schuhe die Füsse nach. Bei drei Abbildern (U1602, U1603, U1627) gibt es auch einen aus Stoff hergestellten Kopf, aber die Gesichtszüge sind nicht erkennbar. Zwei Abbilder (aus Obdorsk) sind in kleine Wiegen hineingelegt (U1638 und U1639). Ahnliche Totenabbilder, die in einer Wiege liegen, sind auch aus einer Beschreibung von N. Podrewski $(1895,168)$ bekannt. 
Im Nationalmuseum in Helsinki finden sich Totenabbilder, die 1911 von T. V. Lehtisalo bei den Chanten vom niederen Ob gesammelt wurden. Drei solcher Abbilder wurden in einer Tasche aus Rentierfell (SKM, Nr. 4899-144) aufbewahrt. Zwei davon stellen die tote Mutter und die tote Tochter des Chanten Gawriil Sekow vom Fluss Poluj dar. Die Masse des Abbildes betragen 10,11 und 12,5 cm. Es ist aus kleinen offenen Pelzen gefertigt, Kopf und Gesicht sind aus Stoff und auf dem Kopf befindet sich ein Tuch. Am Kopf sind Zöpfe befestigt, die aus Wollfäden geflochten sind und durch Kettchen verziert sind. Um das Gesicht eines Abbildes ist ein Glasperlenfaden genäht, der bis auf die Brust hinabreicht. Zur Sammlung von Lehtisalo gehört auch eine Gruppe von zehn Totenabbildern des Schamanen Etaptschi Jachatschi und seiner Verwandten, die alle Chanten waren (wahrscheinlich vom Poluj). Drei von ihnen haben Füsse (SKM, Nr. 4894-137, 140, 142). Die Körper der Abbilder der toten Männer sind aus einer Maliza mit einer Kapuze hergestellt, über die Kattun-Malizahemden gezogen sind, und diese wiederum sind mit Stoffbändern verschnürt, das weibliche Abbild ist mit einem Pelz bekleidet. Die Masse der Totenabbilder betragen $10 \times 5,5,12 \times 5$, $13 \times 7 \mathrm{~cm}$. Die anderen Seelenbehausungen haben einen Holzkörper.

Offensichtlich hatten die Totenabbilder keinen Körper, die von I. N. Schuchow im Tal des Flusses Schtschutschja (Jamburinsker Flussarm) im Jahre 1913 bei den Chanten aufgezeichnet wurden (MAE, Nr. 2535). Der Kopf und das Gesicht dieser Seelenbehausungen sind, soweit das aus den Zeichnungen zu erkennen ist, aus Stoff genäht. Beide Abbilder sind, wie aus den Bildunterschriften ersichtlich, männlich, jedoch ist eines in eine Maliza, das andere in eine offene Bekleidung gehüllt. An der Maliza ist ebenfalls die Andeutung eines vertikalen Schnittes wie an der offenen Bekleidung zu erkennen. Die Kleidung ist mit Ringen, Ketten und Knöpfen verziert.

N. F. Prytkowa beschreibt zwei Exponate aus den Sammlungen des MAE, die aus zusammengebundenen Miniaturbekleidungsstücken bestehen (Prytkowa, 1971, 108-109). Sie zählt sie zu den Opfergaben. Es ist anzunehmen, dass es spezifische Totenabbilder sind, die aus Bekleidungsstücken bestehen, wie wir das an der Synja in der Siedlung Nimwoschgort (Abb. 2) gesehen haben. Ein Fall der Aufbewahrung einesTotenabbildes von tragisch ums Leben Gekommenen im Haus des Verstorbenen wurde von mir am Kunowat (Sokolowa 1975 b, 171) verzeichnet. Das Totenabbild war wahr- 


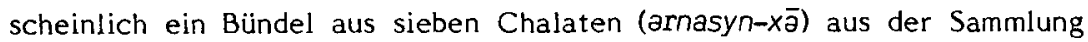
von I. N.Schuchow (Kazym oder Poluj), das am Baum in der Nähe des Hauses hing (MAE, Nr. 2416-6, 7). Dem zweiten Teil der Benennung muss besondere Aufmerksamkeit geschenkt werden: $x \bar{\partial}$ 'Mensch' (die Bekleidung stellte einen Menschen dar). Ein Totenabbild aus Stoff mit einem gläsernen Pfropfen an der Stelle des Kopfes wird im SME aufbewahrt (Iwanow, 1970, 40). Uber Totenabbilder aus Stoff mit einem Metallplättchen an der Stelle des Gesichtes schrieben L. Beketow und M. Kowalski (Kowalski 1853, XXVII; Beketow 1857, 106). Solche Totenabbilder bei den Nenzen beschrieb L. W. Chomitsch (Chomitsch 1971, 244, 245). S. W. Iwanow beschreibt die Totenabbilder bei den Kazym-Chanten; sie sind aus Stoff genäht und die Gesichter sind gestickt (Iwanow 1970, 40). K. F. Karjalainen berichtet von anderen Totenabbildern bei den Kazym-Chanten: Sie wurden ebenfalls aus Stoff hergestellt, und an der Stelle des Kopfes wurden vom Toten abgetrennte Haare befestigt. Manchmal gab es an der Stelle des Gesichtes eines solchen Abbildes ein Metallplättchen (Karjalainen 1921, 143; Tschernezow 1959, 150; Iwanow 1970, 36).

Unter den Museumssammlungen der Totenabbilder trifft man oft solche, die einen Holzkörper aufweisen. In der Sammlung von S. I. Rudenko gibt es drei solcher Abbilder von verstorbenen Chanten (songüt-xarl) vom Unteren Ob (Siedlungen Sjansy und Labytnangi). Das sind kleine, $15-16,4 \mathrm{~cm}$ grosse, hölzerne anthropomoprhe Figuren mit kaum angedeuteten Füssen und Kopf (SME, Nr. 1711-461, 462, 1909-1910). Zwei davon sind von S. W. Iwanow veröffentlicht worden (Iwanow 1970, 32, Abb. 27, 3). Die dritte (SME, Nr. 1711-463) weist ein Gesicht aus einem Kupferknopf auf; der Kopf ist in rotes Tuch gehüllt, an dem Kupferketten mit Ringen befestigt sind. Dieses Abbild wurde in einem Grab gefunden. Andere hölzerne Totenabbilder in der Sammlung von S. I. Rudenko - ngütürma - sind Seelenbehausungen von toten Schamanen und Schamanenfrauen. Nach seinen Angaben sind diese Leute unsterblich (wie die Chanten und Nenzen annahmen). Bei den Chanten werden solche Abbilder mit lon songüt, bei den Mansen mit ittarma und bei den Nenzen mit ngütürma oder itürma bezeichnet. Sie werden eine unbestimmte Zeit lang im Haus in speziellen Kisten, ngütürma-larasj (Nenzen), aj-larasj (Chanten), aufbewahrt (Rudenko 1972, 55; SME, Nr. 1711-57; Photothek Nr. 1707-47, 50). Zwei Abbilder von verstorbenen Schamanen aus 
den Siedlungen Sumut-nel und Pam-pugol am Unteren Ob sind hölzerne Figuren mit Kopf, ohne Füsse, mit angedeuteten Händen in Form von abgehauenen Holzstücken, mit geritzten oder ausgeschnittenen Gesichtszügen (SME, Nr. 1711-513), in einem Fall bildete ein Stock den Körper (SME, Nr. 1711-531). Sie sind in eine Maliza mit einer Kapuze gekleidet. Die Grösse der Abbilder beträgt von 15 bis $23 \mathrm{~cm}$. In der Kiste lagen sie auf einer Pelzunterlage. Das dritte Totenabbild aus der Chantensiedlung Etlog-gort bei Obdorsk (Salechard) ist eine verstorbene Schamanin. Anstelle des Gesichtes dieser Figur war ein Kupferknopf angebracht. Die Figur ist in einen kurzen schwarzen Tuch-Gus gekleidet, darüber ist ein Pelzmantel-Sach mit befranstem Tüchlein als Gürtel gezogen, um den Kopf befindet sich ein Tuch. An der Kleidung ist ein Fingerhut befestigt. Die Grösse der Figur beträgt 18 $\mathrm{cm}$ (SME, Nr. 1711-626). Ein weiteres Abbild aus Amderma ist das eines Nenzen. Es ist eine hölzerne Figur mit Füssen (sogar die Fusssohlen sind ausgeschnitten), mit Händen in Form von abgehauenen Holzstücken. Die Augen und der Mund sind ausgeschnitten, und die Nase steht hervor. Die Figur ist in zwei Pelzmäntel ohne Futter gekleidet, die mit einem kleinen Votivtuch aus Seide mit Fransen aus Garn zusammengehalten werden. Das ist die "Grossmutter", sie war einer Nenzin geschenkt worden, und zwar von ihrer Schwiegermutter und wurde "vor etwa 100 Jahren" angefertigt (SME, Nr. 1711-626).

In einem Grab wurde auch ein anderes Totenabbild aus Holz gefunden. Dieses Abbild entdeckte Sommje bei Surgut (Karjalainen 1921, 141). Es wurde auch von S. W. Iwanow veröffentlicht (Iwanow 1970, 38, Abb. 26). Es handelt sich um eine menschliche Figur ohne Füsse. Wahrscheinlich war sie bekleidet, die Kleidung aber vermoderte. Um ein Totenbild handelte es sich zu Anfang höchstwahrscheinlich auch beim Abbild des Urgrossvaters von Iwan Sopytsch vom Fluss Agan, welches von R. P Mitusowa im SME (SME, Nr. 4047-309) abgegeben und von S. W. Iwanow veröffentlicht wurde (Iwanow 1970, 46, Abb. 33). Es handelt sich dabei um eine hölzerne menschliche Figur von $18 \mathrm{~cm}$ Grösse, die in einige offene Kleidungsstücke aus Tuch und Kattun gekleidet war. Sie wurde in einem Grabhäuschen in der Nähe des Hauses (der Jurte Tumury-pugol) gefunden.

Im MAE werden Totenabbilder von Obdorsker Chanten aufbewahrt, die aus Holz hergestellt sind (Iwanow 1970, 39, Abb. 27-1, 4). Das eine ähnelt 
dem Abbild songüt-xarl aus der Sammlung von S. I. Rudenko; der Körper ist mit Stoff umhüllt. Das andere besitzt keine Hände und keine Füsse und befindet sich am Bug eines Miniaturbootes. Höchstwahrscheinlich war die im Heimatmuseum der Chanten und Mansen aufbewahrte hölzerne Figur eines Schamanen in Nationaltracht und mit Schamanenkopfbedeckung (Grösse 27 $\mathrm{cm}$ ) auch ein Totenabbild. Einem Totenabbild ähnelt auch eine andere anthropomorphe hölzerne, mit zwei Hemden und einem Chalat bekleidete Figur (Grösse $32 \mathrm{~cm}$ ), die als lonx bezeichnet wird (Bestände des Heimatmuseums der Chanten und Mansen, Nr. 240, 256).

Eine umfangreiche Sammlung von hölzernen Totenabbildern wurde von T. V. Lehtisalo bei den Chanten am Unteren Ob erworben. Es sind die Abbilder des oben bereits erwähnten Schamanen Etaptschi Jachatschi und seiner Verwandten (SKM, Nr. 4899-133-136, 138, 139, 141). Es handelt sich um sieben Abbilder. Ihren Körper bildet eine hölzerne Figur ohne Hände und Füsse von 8,5 cm Grösse (SKM, Nr. 4899-138) oder eine hölzerne Büste von 6 cm Länge (SKM, Nr. 4899-141), in anderen Fällen ist es ein einfacher gehobelter Span, der manchnal in der Höhe des Kopfes zugespitzt ist, von 5 bis 7 oder $8 \mathrm{~cm}$ Länge und von 1,5 bis 2 oder $3 \mathrm{~cm}$ Breite. Uber den hölzernen Körper ist eine Miniaturkleidung gezogen, und zwar bei den Abbildern der Männer eine Maliza mit einer Kapuze und ein Kattun-Malizahemd, das mit einer Wollschnur zusammengebunden ist; die Abbilder der Frauen sind in einen Pelzmantel und ein Kattuntuch gekleidet. Die Masse der bekleideten Figuren betragen $12 \times 6,15 \times 9,18 \times 8,22 \times 7,18 \times 10$ und $21 \times 11 \mathrm{~cm}$. Bei einem Abbild ist an der Stelle des Gesichtes ein Knopf (SKM, Nr. 4899-133), bei einem anderen ist ein Metallplättchen einer industriell hergestellten Schachtel (SKM, Nr. 4899-138) angebracht. Aus dem Blech derselben Schachtel (auf dieser sind Buchstaben von der Aufschrift erhalten geblieben) wurde das Kopftuch für das andere Abbild einer verstorbenen Frau angefertigt (SKM, Nr. 4899-139). In der Sammlung von Lehtisalo gibt es auch andere hölzerne Totenabbilder der Chanten. Eins davon ist das Abbild eines Mannes, der 1908 verstorben ist. Es stellt eine hölzerne Figur mit Füssen und einem runden Kopf dar. Am Gesicht sind Augen, Nase und Mund ausgeschnitten. In die Augenhöhlen sind blaue Glasperlen eingesetzt. Die Figur ist mit einem schwarzen Tuch-Gus mit einer Kapuze und mit gleichartigen Strümpfen bekleidet. Mit ihr zusammen wurde ein Messer in der 
Scheide aufbewahrt (SKM, Nr. 4899-129), s. Abb. 11. Ein anderes Abbild stammt vom Fluss Poluj, dieses verkaufte der Chante Konstantin Sekow. Es ist eine hölzerne Figur von $20 \mathrm{~cm}$ Grösse, die mit Kattunlappen umhüllt und mit einer Maliza mit Kapuze bekleidet ist. Die Gesichtszüge sind nicht angedeutet, s. Abb. 12 (SKM, Nr. 4899-131). Das Abbild des im Jahre 1905 verstorbenen Vaters des Chanten Ljaschkin aus der Siedlung Wylposl-pugol wurde zu Hause in einer Schachtel aufbewahrt. Es bekam jeden Tag "Essen". Es ist eine hölzerne Figur (Grösse $18 \mathrm{~cm}$ ) ohne Hände, mit Füssen ohne Fusssohlen. Die Augen und der Mund sind eingeritzt. Die Figur ist in ein Stück Stoff eingewickelt, darüber ist eine geschlossene Lederbekleidung mit einer Kapuze, ein Tuch-Gus und darüber noch ein Gus gezogen, der aus einem dicken Stoff und aus Tuch unterschiedlicher Farben (rot, blau und gelb) genäht und mit Pelz besetzt ist, Abb. 13 (SKM, Nr. 4899-149). Der Schamane Rajk aus dem Geschlecht Poronguj bewahrte das Totenabbild der Mutter seiner Frau aus der Sippe Charka Mejeko Kari auf. Es handelt sich um eine hölzerne Figur mit Füssen, die Gesichtszüge sind eingeschnitten. Sie ist mit einem Pelzmantel bekleidet, der mit einem Wollgürtel zugeschnürt ist, an dem ein Blechschildchen hängt. Das Abbild wurde in einer Pelztasche aufbewahrt (SKM, Nr. 4899-143). Noch ein Totenabbild mit dem durch eine Münze bezeichneten Gesicht ging vom Vater an die Tochter über, vom vor langer Zeit verstorbenen Chanten Chonde (Siedlung Wylposl-pugol). Das Abbild wurde jedoch noch zu Hause in einer Schachtel aufbewahrt und mit "Essen" versorgt. Sein Körper ist aus einem Span angefertigt, dieser ist in Stoff- und Fellstücke eingewickelt, darüber ist ein Tuch-Gus aus mehrfarbigem Stoff (rot, gelb, blau und schwarz) gezogen. Die Kapuze ist aus Fell. Das Abbild ist 15,5 cm gross (SKM, Nr. 4899-151). Ein anderes Abbild von dem "vor etwa 10 Jahren" (ungefähr 1901) verstorbenen alten Chanten Nanoku bekam Lehtisalo von dessen Besitzer geschenkt, nachdem dieser ein neues Abbild angefertigt hatte. Das alte und das neue Abbild wurden noch mit "Essen" versorgt. Lehtisalo schreibt, dass im Verlauf von drei Jahren nach dem Tod eines Menschen sein Abbild (Seelenbehausung) als siderjang und nach Ablauf dieser Zeit als niterma bezeichnet wird. Die hölzerne Figur mit einem Zinnschildchen als Gesicht wurde in einen Stofflappen aus Wolle eingewickelt, worüber eine Pelzmaliza mit einer Tuchkapuze gezogen ist, s. Abb. 14 (SKM, Nr. 4899-150). Das Abbild des Chantenurvaters mit dem 
Spitznamen Jadatschi (Jadatschi bedeutet Haken; Porogujew wurde mit einem Haken zusammen abgebildet) wurde als Schutzgeist aufbewahrt. Es ist eine hölzerne Skulptur mit einem runden Kopf, im flachen Gesicht sind eine herausragende Nase, Mund und Augenlöcher ausgeschnitten. Er ist in einer geschlossenen Lederkleidung mit einer Kapuze und einem Ledergürtel verhüllt, an den Füssen trägt er schwarze Tuchstrümpfe. Hinter dem Gürtel befindet sich ein Haken aus Eisen (SKM, Nr. 4899-130).

Unter den Totenabbildern der Nenzen aus der Sammlung von T. V. Lehtisalo gibt es viele aus Holz. Lehtisalo berichtet, dass der Brauch, die Totenabbilder herzustellen und aufzubewahren, nur für die Nenzen vom ob charakteristisch sei, diese hätten den Brauch von den Chanten entlehnt. Das Totenabbild der Mutter des Nenzen Grigorij Iwanowitsch wurde in einer Truhe, die industriell hergestellt war, mit den Massen $25 \times 16 \times 7 \mathrm{~cm}$ aufbewahrt. Auf der Innenseite des Deckels ist ein Kreuz (möglicherweise mit dem Blut eines Opfertieres) aufgezeichnet. Auf dem Boden der Truhe lagen Fellstücke von Rentieren und anderen Tieren, ein Säckchen aus Kattun und ein Tuchlappen. Das Abbild besitzt keine Hände, ist aber mit Füssen versehen. Das Gesicht am runden Kopf bestand aus einer geraden Spitze, die Augenhöhle und der Mund waren eingeritzt. Das Abbild ist in Kattunstoff eingewickelt, welcher ein Kleid und ein Tuch darstellt. Uber dem Stoff finden sich ein offener Chalat aus rotem, blauem und gelbem Tuch mit Applikationsstreifen geschmückt und ein Pelzmantel aus abgenutztem Rentierfell. Die Kleidung ist mit einem Gürtel aus Wolle versehen. Dieses Abbild wurde mit "Essen" versorgt, abends ausgezogen und "schlafen" gelegt. Das Totenabbild durfte nicht in der Sonne liegen, weil es im Jenseits nach dem Glauben der Nenzen keine Sonne gibt (deshalb haben die Chanten mir nur ungern erlaubt, die Totenabbilder auf der Strasse zu fotografieren). Lehtisalo berichtet, dass nach drei bis vier Jahren das Abbild eines jungen Verstorbenen (siderjang) auf dem Friedhof, eines alten (niterma) dagegen im Haus begraben wird, es wird zum хахә, d. h. zum Schutzgeist (SKM, Nr. 4899-127). Unter den Sachen des Schamanen aus dem Geschlecht Tocho befand sich eine hölzerne Kiste mit vier Totenabbildern (SKM, Nr. 4899-128; im Verzeichnis wurden zwei widersprüchliche Eintragungen gemacht: "Totenabbilder" und "Kinderpuppen eines Schamanen"; richtig ist wahrscheinlich die erste). In der Kiste lagen sie auf einem Rentierfell. Mit diesen 
zusammen befanden sich dort eine runde kleine Mütze aus Baumwolle, die mit grobem Wildleder besetzt ist (wahrscheinlich das Modell einer Schamanenmütze), zwei Fausthandschuhe aus Tuch und ohne Finger, eine geflochtene Schnur, an der ein Glöckchen und eine 5-Kopekenmünze aus dem Jahre 1875 angebunden waren. Alle Abbilder waren aus Holz, darunter drei männliche, die mit einer Maliza mit Kapuze und Malizahemden bekleidet waren, die mit einem Stoffband umgebunden waren. Ihre Masse betragen 15 $\times 5,12 \times 5$ und $9 \times 5 \mathrm{~cm}$. Beim grössten Abbild war am unteren Teil des Körpers ein Säckchen befestigt, das gleichsam die Fortsetzung des Körpers nachbildete. Das Abbild der Frau ist mit einem offenen Pelzmantel, der mit einem Stoffgürtel umwunden ist, und mit einer Mütze bekleidet. Es hat eine Grösse von $14 \times 7 \mathrm{~cm}$, s. Abb. 16 .

Zu der Sammlung von T. V. Lehtisalo gehören auch die Totenabbilder der Eltern des Nenzen Pidi Wanuita Noingod. Die Mutter und der Vater waren beide Schamanen. Das Abbild der Mutter Nekotze Salender stellt eine hölzerne Figur von $19 \times 10 \mathrm{~cm}$ dar mit einem runden Kopf, Füssen und Händen. Auf dem flachen Gesicht sind Augen und Mund eingeritzt. Die Figur ist in einen Tuchstoff gehüllt, der über einem Rentierpelzmantel mit abgeschabtem Fell angebracht war. Am Rockschoss und am Saum ist der Pelzmantel mit rotem Tuch und mit einem Wollgürtel mit Ring ausgeschmückt. Auf dem Kopf sitzt eine Haube aus schwarzem und rotem Tuch, die mit Fell abgesetzt ist. Die Bänder der Mütze sind mit den Enden des langen Mantelkragens aus rotem Tuch verknotet. Die Manschetten an den Ärmeln des Pelzmantels bestehen auch aus gelbem Tuch, die Bänder des Pelzmantels sind aus Baumwolle. Die Masse des Abbildes mit der Kleidung betragen $20 \mathrm{x}$ $11 \mathrm{~cm}$ (SKM, Nr. 4899-147). Das Abbild des Vaters von Pidi Wanuit namens Chatawa Wanuit ist auch aus Holz. Es ist eine Büste von $6 \mathrm{~cm}$ Grösse, das Gesicht ist ein Blechschildchen aus Kupfer. Das Abbild ist in drei Kattunhemden, eine Maliza mit einer Kapuze und einen kurzen Sowik gehüllt, der mit einem Tuchband verschnürt ist. Auf dem Kopf unter der Kapuze ist ein Lappen aus rotem Tuch zu sehen. Die Masse des Abbildes mit der Kleidung betragen $21 \times 10 \mathrm{~cm}$, s. Abbildung 17 (SKM, Nr. 4899-148). Diesem ähnelt auch ein anderes Abbild (SKM, Nr. 4899-132). Den Körper bildet eine anthropomorphe Figur von $9 \mathrm{~cm}$ Grösse mit einem Kupferknopf anstelle des Gesichtes; unter dem Knopf ist ein Stück Blech angebracht. An der Figur sind 
der Kopf und die Hände nur durch eine Wölbung angedeutet, unten befindet sich der Körper mit einer etwas langgestreckten Form. Die Figur ist mit einer Maliza mit Kapuze und mit einem grünen Malizahemd bekleidet. Ihr Ausmass zusammen mit der Kleidung beträgt $20 \times 13 \mathrm{~cm}$. Sie wurde als niterma bezeichnet.

Das Abbild von Fiektow, dem Vater des Nenzen Nikolai Ngaderin, der etwa 1850 "vor 60 Jahren" verstarb, stellt auch eine hölzerne Figur dar, deren Kopf und Gesicht mit Leder verkleidet sind. Die Hände und Füsse sind nur angedeutet, an den Füssen sind jedoch Fellschuhe vorgefunden worden. Die Figur ist mit einem Pelz-Sowik bekleidet, darüber sind zwei Tuch-Gus gezogen (der obere Gus ist aus gelbem Tuch und die Kapuze ist mit rotem Tuch besetzt). Das Ausmass des Abbildes beträgt zusammen mit der Kleidung $30 \times 13 \mathrm{~cm}$. Es wurde zu Hause zusammen mit den Abbildern der Schutzgeister des Hauses, $x ә x \partial$, aufbewahrt. Im Frühling und im Herbst wurde ihm Fleisch geopfert (SKM, Nr. 4899-146).

Im MAE wird das Totenabbild eines Nenzen-Jägers vom Fluss Tas aufbewahrt, das 1914 von I. N. Schuchow mitgebracht worden war (MAE, Nr. 2407-1; Photothek, Nr. 2421-118). Im Verzeichnis steht, dass es sich um einen Ahnen handelt, der als nütürma bezeichnet wird und während der Jagd hilft ("Handwerks-Götzenbild"). Das Abbild wurde aus Holz hergestellt, für die Augen sind Glasperlen eingesetzt. Es weist keine Kleidung auf, am Gesicht sind Schmalzspuren von der Opferung zu sehen. Das Abbild hat zwei Köpfe und zwei Körper (der zweite stellt seine Frau dar).

Eigenartige hölzerne Totenabbilder der Chanten sind von S. I. Rudenko 1910 vom Unteren Ob mitgebracht worden (Siedlungen Aksarka und Sumutnel). Sie sind ebenfalls aus Holz, werden als songüt bezeichnet, aber der hölzerne Körper des Abbildes wird an einem Behälter oder Körbchen aus Birkenrinde befestigt, mit dem er ein Ganzes bildet. Die Kleidung hat eine solche Grösse, dass sie zusammen mit dem Behälter, der einen Teil des Körpers bildet, über die Figur gezogen wird. Gleichzeitig ist der Behälter für die Aufbewahrung der mit dem Totenabbild zusammen abgelegten Dinge vorgesehen: In den Behältern verschiedener Totenabbilder befanden sich Tabakdosen mit Schnupftabak, die aus Birkenrinde hergestellt sind, Holzlöffel, Gefässe aus Birkenrinde (diese Gegenstände waren 15 bis $17 \mathrm{~cm} \mathrm{lang),}$ Stücke von Rentierfell, Späne mit der Bezeichnung wotleb, eine Pfeife mit 
Rauchtabak in einer Tabakdose, ein Fingerhut, eine Tasse mit Untertasse und ein Messer. In den Gefässen aus Birkenrinde war Fett oder gebackener Teig aufbewahrt (Rudenko 1972, 51-52, Abb. 18, 19). Der Behälter aus Birkenrinde, der am Körper des Totenabbildes befestigt ist, wurde mit Rutenreifen und Stoff verkleidet und an diese wurden Halsketten oder Blechschildchen angenäht. Die hölzerne Figur selbst wurde aus abgehauenen Holzstücken, einem Span oder einer Rute hergestellt. An der Stelle des Gesichts befand sich eine Münze, ein Kupferknopf, ein Blechschildchen oder ein Zinnplättchen und manchmal ein Blechschildchen zusammen mit einem Zinnplättchen. Die Kleidung der Abbilder bestand aus einem Pelzmantel mit Bändern und einem Futter aus Fell oder Tuch, bzw. aus einem rotschwarzen Tuch-Chalat nuj-sach mit Bändern und mit Futter entweder aus Fell oder Stoff, der Gürtel war aus Wolle. Auf dem Kopf befand sich ein Tuch, eine Pelz- oder Haubenmütze aus Tuch und oftmals waren zwei oder drei Kopfbedeckungen übereinander gezogen. Die Haubenmützen hatten lange breite Bänder aus grauem oder grünem Tuch, die bis auf den unteren Teil der Kleidung herabreichten und durch Ringketten, Anhänger aus Halsketten und Blechschildchen verziert waren. Die Grösse der Abbilder zusammen mit der Kleidung beträgt von $17-23$ bis $31-47 \mathrm{~cm}$. Eines dieser Abbilder wurde von N. F. Prytkowa veröffentlicht (1971, 108, Abb. 3). Die Abbilder werden in den Grabhäuschen songüt-hot (Chanten) und siderjang-mja (Nenzen) aufbewahrt (SME, Photothek, Nr. 1706-105-107). S. I. Rudenko gibt folgende Bezeichnungen solcher Abbilder an: bei den Mansen perk pjadu mut, aut akanj, siderjang, bei den Chanten songüt (Rudenko 1972, 51-52, Abb. 20, 21). In einem Grabhäuschen konnten bis zu 10 Totenabbilder aus einer Familie aufbewahrt werden. Sie sassen dort auf einem Sitz aus Rentierfell. Zu Hause wurde das Abbild 2 bis $2 \frac{1}{2}$ Jahre aufbewahrt (nach der sakralen Zeitrechnung der Chanten und Mansen waren es 4 bis 5 Jahre). Diese Abbilder wurden von den weiblichen Verwandten des Verstorbenen (aber nicht von der Ehefrau oder der Mutter) nach seinem Tod angefertigt. Rudenko berichtet, dass vorher durch den Schamanen der "Wille" des Verstorbenen bezüglich des Schicksals seines Abbildes in Erfahrung gebracht wurde: Wenn er "nicht wollte", dass sein Abbild ins Grab gelegt wurde, so wurde dafür ein Grabhäuschen gebaut. 
Ein analoges Abbild ist auch in der Sammlung von Lehtisalo vorhanden. Es ist das Abbild des Sohnes einer Nenzenfrau von 70 Jahren. Der Körper des Abbildes besteht aus Holz und ist mit einem Behälter aus Birkenrinde verbunden, an der Stelle des Gesichts befindet sich ein Kupferschildchen. Im Behälter liegen Fellstücke. Der Behälter selbst ist mit rotem Kattun verkleidet. Auf dem Kopf des Abbildes ist ein roter Tuchlappen befestigt, das Abbild ist in einen schwarzen Tuch-Chalat mit roten Bändern aus Baumwolle gehüllt. Die Masse des Abbildes betragen 31 x $20 \mathrm{~cm}$ (SKM, Nr. 4899-145).

Einige hölzerne Totenabbilder von Chanten und Mansen wurden von W. N. Tschernezow veröffentlicht $(1959$, Abb. 4, 5.) Leider hat der Autor nicht angegeben, wo diese Abbilder aufbewahrt werden. Wahrscheinlich stammen diese Seelenbehausungen moxar, కonat, akanj und itarma aus den Sammlungen des SME und MAE; das eine von ihnen, dargestellt auf Abb. 4, befindet sich am Bug eines Miniaturbootes und wurde auch von S. W. Iwanow aus den Sammlungen des MAE zur Veröffentlichung ausgewählt (Iwanow 1970, 39, Abb. 27-4). Ausser einem Abbild (das in der Mitte von Abb. 4 angebracht ist) bestehen offensichtlich alle anderen aus Holz. Ein Abbild mit einem Körper in Form einer Kiste ist von Interesse (wahrscheinlich handelt es sich dabei wie auch bei songüt-xarl um eine Aufbewahrungsstelle für die das Totenabbild vervollständigenden Gegenstände). Schliesslich kann noch das Beispiel eines hölzernen Totenabbildes erwähnt werden, das von N. F. Wysotski 1908 und von S. W. Iwanow 1970 veröffentlicht wurde (Wysotski 1908, 256; Iwanow 1970, 39-40, Abb. 28). Es wird im Kasansker Museum aufbewahrt und stellt eine hölzerne Figur einer Mansenfrau in einer Maliza dar. Stirn und Gesicht des Abbildes sind mit einem Stück Rentierfell bedeckt. Seine Länge beträgt $60 \mathrm{~cm}$, es ist das grösste der uns bekannten Totenabbilder. Es scheint angebracht, in dieser Hinsicht den Bericht von G. Nowitzki darüber zu erwähnen, dass dem hölzernen Totenabbild die Kleidung angezogen wurde, die der Verstorbene zu Lebzeiten getragen hat (Nowitzki 1884, 45-46). Daraus lässt sich schliessen, dass die Totenabbilder früher gross waren und möglicherweise Menschengrösse aufwiesen.

Darüber, dass die Totenabbilder aus Holz hergestellt wurden, berichten viele Autoren (Pallas 1778, 78; Beljawski 1883, 98-99; Eirie 1839, 85; Schawrow 1871, 12; Starzew 1928, 124; Tschernezow 1959, 148 u. a.). Nach dem Bericht von W. F. Sujew zu urteilen, hatten diese unterschiedliche 
Formen: "Der von Menschenhand geschaffene Gott war klein und konnte sowohl aus einer Schachtel als auch aus einem Stock oder Knüppel, oder aber aus einem Knebel oder Holzkeil angefertigt sein... Man glaubt, dass die Götzen von den Ahnen abstammen..." (Sujew 1947, 41). Sommje sah die Totenabbilder in den Wohnhäusern der Chanten. Es waren hölzerne anthropomorphe Figuren von 20 bis $30 \mathrm{~cm}$ Grösse, die aus Holzklötzen angefertigt wurden. Sie waren mit Chalaten und Haubenmützen bekleidet, am Hals hingen eine Kette und Ringe an einem Band, und das Abbild wurde in ein Tuch eingewickelt. Im Haus liess man es auf einem Stück Rentierfell am Feuer sitzen. $\mathrm{Zu}$ den Füssen des Abbildes wurden eine Tabakdose, Stoffoder Tücherbündel und ein Holzteller plaziert. Es wurde "mit Essen versorgt", abends "schlafen" gelegt. Das Abbild wurde Sonat genannt. Nach Ablauf einer Frist für die Aufbewahrung des Totenabbildes im Hause wurde dieses zusammen mit dem Verstorbenen begraben (Karjalainen 1921, 141142). W. W. Bartenjew beschreibt die Totenabbilder, die aus Ruten angefertigt waren, und wo an der Stelle des Kopfes ein Knopf befestigt war. Die Grösse eines solchen Abbildes beträgt 17 bis $18 \mathrm{~cm}$ und ist mit Sommer-oder Winterkleidung versehen (Bartenjew 1895, 491). N. L. Gondatti schreibt, dass die Nenzen und Chanten vom Unteren Ob die Totenabbilder aus Birkenrinde, Holz und Fellen anfertigten. Manchmal wurde das Gesicht des Abbildes ausgeschnitten und mit verschiedenen Farben bemalt (Gondatti 1888, 43). Nach den Angaben von G. D. Werbow wurden die Totenabbilder bei den Chanten vom Unteren $\mathrm{Ob}$ und den assimilierten Nenzen aus Espe hergestellt und mit Birkenrinde beklebt; manchmal wurden in die Augenhöhlen Kupferknöpfe hineingesteckt (Tschernezow 1959, 148).

Aus den Museumssammlungen sind auch einige metallische Totenabbilder bekannt. Eines davon stellt eine Frauenfigur mit zugespitztem Kopf, mit Händen und Füssen dar. An der Figur sind die Augen und die Geschlechtsmerkmale angedeutet (Tschernezow 1959, Abb. 4). Im Ethnographischen Museum in Budapest gibt es in der Sammlung von J. Pápay ein Totenabbild mit der Bezeichnung lonx aus den Jurten Askort vom Unteren Ob (Néprajzi múzeum, Nr. 31782). Es wurde im Buch von Gy. Képes veröffentlicht (Gy. Képes 1972, s. Farbfotos auf den Seiten 48-49). Der Körper dieses Totenabbildes ist aus Blei gegossen und hat die groben Umrisse eines rechtwinkligen Körpers mit einem abgerundeten Kopf. Den Körper umhüllen ein Kat- 
tunhemd, ein roter Tuch-Gus mit einer grünen Absetzung und eine Kapuze. Darüber ist ein Chalat aus rotem Kattun mit Fausthandschuhen aus Stoff anderer Farbe gezogen.

Als Totenabbilder wurden in der Sammlung von T. V. Lehtisalo (Suomen Kansallismuseo) auch drei Puppen mit Köpfen aus Entenschnäbeln bezeichnet. Ihre Herkunft ist unbekannt, die Masse und die Kleidung sind jedoch die gleichen wie die der Totenabbilder $(20 \times 10,15 \times 16,15 \times 17 \mathrm{~cm})$ : Maliza mit Kapuze und ein Tuch-Gus (SKM, Nr. 4899-152-154). In einem Fall ist der Knochen des Entenschnabels mit Stoff verkleidet. In der Regel waren solche Puppen bei Chanten und Nenzen Kinderspielsachen. Möglicherweise waren auch diese Gegenstände Spielsachen und werden irrtümlich im Verzeichnis der Totenabbilder aufgeführt.

Demzufolge waren die Totenabbilder in ihrer Form äusserst vielfältig. In diesem Zusammenhang lassen sie sich in folgende Typen und Varianten einteilen:

1. Aus Kleidungsstücken hergestellt:

1.1. Aus Kleidung, die übereinander angezogen und miteinander verbunden ist (Lehtisalo, MAE -Prytkowa, MAE - Schuchow, Prytkowa, Podrewski, Sokolowa, Chomitsch, Tobolsker Museum);

1.2. aus Kleidung mit einer Münze oder einem Metallplättchen an der Stelle des Gesichts (Sokolowa, Chomitsch);

1.3. aus Kleidung mit aus Stoff genähtem Kopf und Gesicht (Lehtisalo, Schuchow, Tobolsker Museum);

1.4. aus Kleidung mit einem Glaspfropfen anstelle des Kopfes (SME Iwanow);

1.5. aus der Kleidung des Verstorbenen (Patkanow).

2. Aus Stoff hergestellt (aus den Beschreibungen geht nicht immer hervor, woraus das Totenabbild hergestellt wurde, entweder aus Kleidungsoder Stoffstücken);

2.1. Mit einem Kopf aus Stoff (?), einem gestickten Gesicht (Iwanow);

2.2. mit einem Metallplättchen oder einem Knopf anstelle des Gesichts (Beketow, Kowalski, Chomitsch);

2.3. mit den Haaren des Verstorbenen auf dem Kopf (Iwanow, Karjalainen, Sokolowa, Tschernezow).

3. Aus Holz: 
3.1. Von grober Bearbeitung, anthropomorph, ohne Gesichtszüge (SME Iwanow, Sujew, Lehtisalo, Rudenko);

3.2. mit ausgeschnittenen oder geschnitzten Gesichtszügen, mit Händen, Füssen bzw. ohne (Beljawski, Sujew, Karjalainen, Lehtisalo, MAE - Schuchow, Mitusowa, Nowitzki, Pallas, Patkanow - Karjalainen, Rudenko, Sokolowa, Sommje - Iwanow, Starzew, Tschernezow, Schawrow, Eirie, Museum der Chanten und Mansen);

3.3. mit einer Münze, einem Blechschildchen, Knopf oder Metallplättchen an der Stelle des Gesichts (Bartenjew, Lehtisalo, Rudenko, Sokolowa);

3.4. mit einer Münze, einem Blechschildchen, Knopf oder Metallplättchen an der Stelle des Gesichts und mit einem Körbchen-Körper als Aufbewahrungsort (Lehtisalo, Prytkowa, Rudenko);

\section{5. mit Birkenrinde beklebt (Werbow);}

3.6. mit einem Kopf und Gesicht, die mit Leder oder Fell verkleidet sind (Wysotski, Lehtisalo);

3.7. in einer Wiege oder einem Boot (SME - Iwanow, Podrewski, Tschernezow, Tobolsker Museum).

4. Aus Metall:

4.1. Anthropomorph: a. mit eingeritzten Gesichtszügen (Sokolowa, Tschernezow, Museum in Budapest);

b. mit einer Münze an der Stelle des Gesichts (Sokolowa);

\subsection{Zoomorph (Sokolowa, Tschernezow).}

$\mathrm{Zu}$ den altertümlichsten Formen zählen wahrscheinlich die Totenabbilder aus Holz und Metall: Die nur aus Kleidungsstücken bestehenden Totenabbilder wurden grundsätzlich erst zu einem späteren Zeitpunkt (Ende des 19. Jahrhunderts, öfter jedoch im 20. Jahrhundert) beobachtet. Man kann sich kaum mit Karjalainen einverstanden erklären, der meinte, dass sich der Brauch, die Totenabbilder herzustellen, aus der Vorstellung darüber entwickelte, dass der Verstorbene in den ihm gehörenden Sachen (z. B. in der Kleidung) auch nach dem Tode anwesend ist (Karjalainen 1921, 175-176). Tschernezow (1959, 155) meinte, dass dieser Brauch aus einem anderen Grund entstanden sei, und zwar durch die Isolierung der Lebenden von den Toten (mit Entstehung des Brauches, die Toten nicht im Wohnhaus, sondern ausserhalb der Behausung zu beerdigen). Solche Vorstellungen existierten natürlich. Es scheint aber, dass der Brauch, die Totenabbilder anzufertigen, 
in erster Linie mit den Vorstellungen über die wiederauflebende Seele verbunden ist. Diese soll im Totenabbild solange beherbergt werden, bis sie wieder auferstanden ist. Es ist kein Zufall, dass die Aufbewahrungsdauer für die Totenabbilder, die sich im Hause befinden, mit dem Zeitraum im Zusammenhang steht, der für die Wiederauferstehung der Seele gilt; das sind 4 bis 5 Jahre nach der sakralen Zeitrechnung, oder 2 bis $2 \frac{1}{2}$ Jahre nach der gebräuchlichen Zeitrechnung ( 1 Jahr ist so lang wie ein halbes Jahr) (Bartenjew 1895, 491; Rudenko 1972, 54; Sokolowa 1974, 50; Sokolowa 1976 b, 398). Der Brauch der Chanten vom Irtysch besagt, dass unter dem Kopfkissen des Verstorbenen seine nicht gewaschene Wäsche und sein Laken aufbewahrt werden und bei der Gedenkfeier diese auf dem Kopfkissen als Verkörperung des Verstorbenen darzubieten sind (Patkanow, 1897, 145; in Ungarn wurde mancherorts ebenfalls das Bett des Verstorbenen aufbewahrt, die Witwe oder der Witwer legten sich darin schlafen, um im Traum den Wunsch des Verstorbenen zu erfahren - Karjalainen 1921, 176), aber nicht, dass sie keine Totenabbilder besassen, sondern, dass sie diese nicht mehr herstellten und an deren Stelle die Wäsche benutzten. Wahrscheinlich fertigten die Chanten vom Irtysch früher Totenabbilder in Menschengrösse an (schon Nowitzki wies darauf hin) und bekleideten sie mit der Kleidung der Verstorbenen.

Auf diese Weise dient nach dem Tod eines Menschen sein Abbild als Aufenthaltsort für die reinkarnierende Namen-Seele bis zu ihrer Einsiedlung in einem Neugeborenen (Tschernezow 1971, 81). Zu dieser Art der Abbilder zählte W. N. Tschernezow auch die Figuren aus Flachguss, die von den Archäologen an Schatz-Aufbewahrungsorten sowie in speziellen Grabstellen neben der Siedlung gefunden wurden (Tschernezow 1941, 26; 1953, 174-178, 222-223; 1959, 156; 1971, 80-81; Starkow 1973, 219; Sokolowa 1975 c, 50; 1975 a, 147). Solche Metallfiguren, die entweder Tiere und Menschen darstellten oder zooanthropomorph waren, unterschieden sich bei verschiedenen Gruppen der Vorfahren von Chanten und Mansen. W. N. Tschernezow meinte, dass jede genealogische, ursprünglich Totemgruppe über Sammlungen solcher Abbilder, von Namen-Seelenbehausungen also, verfügte, die in den Tempeln oder an speziellen Aufbewahrungsplätzen aufgehoben wurden. Eines der Totenabbilder, das ich in der Siedlung Gorbungort gefunden hat te, war sehr primitiv aus Bleiguss (möglicherweise aus Schrot) hergestellt, die zoomorphe 
Art war bei diesem besonders ausgeprägt, s. Abb. 5 f. Es ähnelt mehr als die anderen den Figuren aus Flachguss. Es ist auch möglich, dass die Bewohner der Siedlung Schischingi die Totenabbilder in Gestalt eines Frosches anfertigten, der ihr Totem darstellte. Dafür spricht der Fund eines Froschabbildes, das aller Wahrscheinlichkeit nach ein Totenabbild darstellte (s. oben, Sokolowa 1975 a, 146-147). Mir ist ferner bekannt, dass in früheren Zeiten (daran erinnern sich noch die Alten) die Bewohner der Siedlung Lopchari die Totenabbilder in Gestalt einer Lärche herstellten.

Offensichtlich wurden früher die Gesichtszüge, d. h. Augen, Nase und Mund, unbedingt auf dem Gesicht des Abbildes eingetragen, da nur in einem solchen Abbild (mit den Augen) die Totenseele leben konnte. (Eine unerlässliche Bedingung für die Kinderpuppen als Spielsachen ist das Fehlen von Augen und anderen Gesichtszügen. Nebenbei bemerkt haben die ungarischen Kinderpuppen, die als Spielzeug dienten und die im Ethnographischen Museum in Budapest aufbewahrt werden, auch keine Gesichter.) Möglicherweise hat man früher das Gesicht des Totenabbildes immer mit einem Stück Leder, Stoff, mit einer Münze, einem Blechschildchen, Knopf oder Metallplättchen bedeckt, die die Bedeckungs-Totenmaske imitieren sollten. Allmählich ging man dazu über, dass eine Münze, ein Blechschildchen, Knopf oder Metallplättchen das Totengesicht selbst imitierten. Das war jedoch offensichtlich nur für anthropomorphe Totenabbilder charakteristisch.

Ungeachtet dessen, dass es einige gemeinsame Verfahren bei der Herstellung der Totenabbilder gibt, fällt dennoch das Fehlen von gemeinsamen kanonisierten Formen und ihre Vielfalt auf. Das lässt sich dadurch erklären, dass die Herstellung eines Totenabbildes und seine Verehrung als eines Ahnenbeschützers die Angelegenheit jeder einzelnen genealogischen Gruppe und später der Familie war. Der Kult der Totenabbilder und Ahnenbeschützer stellte einen sakralen Kult und ein Tabu für die Mitglieder anderer genealogischen Gruppen und Familien dar. Ubrigens wies auch W. N. Tschernezow auf den lokalen Charakter hin, den die Ausgrabungen der als Totenbilder identifizierten Figuren aus Flachguss aufweisen (1953, 222-223). Gerade deswegen gibt es so oft Abwandlungen bei ihrer Herstellung. Ihre Masse schwankten auch abhänging davon, welche in dieser oder jener Gruppe bzw. Familie gebräuchlich waren, später jedoch (19. bis 20. Jahrhundert) bewegten sich die Masse in den Grenzen von 15 bis $30 \mathrm{~cm}$. Der Hinweis von 
M. Kowalski darauf, dass ihre Grösse vom Alter des Verstorbenen abhing, wurde von niemandem mehr bestätigt. I. P. Rosljakow schreibt jedoch, dass das Totenabbild wie der Verstorbene selbst wächst, indem er im Jenseits seine Kinder- und Jugendjahre noch einmal durchlebt. Im Verlaufe eines Mondjahres, solange wie das Totenabbild zu Hause aufbewahrt wird, erreicht der Verstorbene das Alter, in dem er vom jenseitlichen Eigentum Besitz ergreifen kann (Rosljakow 1896, 5). Aber auch diese Angaben sind noch nicht ganz geklärt und werden von niemandem mehr bestätigt.

Die Totenabbilder trugen stets die Winterkleidung, d. h. sie hat ten eine komplette Kleidungsgarnitur, of tmals mehrere Garnituren. Zu Anfang bekam das Totenabbild wahrscheinlich éine Kleidungsgarnitur, aber während der Zeit, in der es zu Hause aufbewahrt wurde, nähten die Familienmitglieder und die Verwandten, die das Totenabbild besuchen kamen, neue Garnituren als Votiv-Kleidung, welche dem Totenabbild angezogen oder neben diesem als Geschenk hingelegt wurden. Es ist von Interesse, dass bei männlichen Totenabbildern offene Kleidungsstücke vorgefunden wurden (erinnert sei an die von I. N. Schuchow gemachten Zeichnungen der Totenabbilder und die Totenabbilder in den Sammlungen von Lehtisalo, Nr. 4899-137: Im Verzeichnis wird angegeben, dass es sich um einen Mann handelt, der keine geschlossene, sondern eine offene Kleidung trägt. Vgl. auch das Abbild des Urgrossvaters von Iwan Sopytsch vom Fluss Agan, MAE, Nr. 4047-309). Das sind Ausnahmen, die jedoch das Alter der offenen Bekleidung bezeugen können (noch öfter waren offene Kleidungsstücke bei den männlichen Abbildern von Schutzgeistern vorzufinden; Prytkowa 1971). Den Totenabbildern brachten die Verwandten Arbeitswerkzeuge, Tabakdosen, Rauchpfeifen, Geschirr mit Lebensmitteln u. a., was ihnen zu Lebzeiten gehört hatte, als Geschenk dar.

Die Methoden der Aufbewahrung der Totenabbilder nach Ablauf der Frist der Verwahrung zu Hause sind vielfältig. Die Unterschiedlichkeit drückt sich darin aus, dass diese Abbilder:

1. beerdigt werden (Tschernezow, Schawrow), in einem Grab (Karjalainen, Castrén, Lehtisalo, Podrewski, Rosljakow, Rudenko, Sommje, Schuchow), auf dem Friedhof (Werbow, Sokolowa) oder in der Erde (es ist nicht immer geklärt, wo und wie die Totenabbilder beerdigt werden; Andrejew, Beljawski, Kowalski, Nowitzki, Eirie); 
2. vergraben werden, und zwar in der Erde, im Wald (Rosljakow, Sokolowa);

3. in den Grabaufbau getan werden (Rosljakow, Starzew);

4. im Wald weggeworfen werden (Sokolowa);

5. aufgehängt werden, und zwar an einem Baum im Wald (Sokolowa) oder in der Nähe des Hauses (Schuchow, Prytkowa);

6. verbrannt werden (Karjalainen, Tschernezow);

7. in einem Grabhäuschen aufbewahrt werden (Bartenjew, Beketow, Kowalski, Rudenko, Sokolowa, Finsch und Brem, Tschernezow);

8. auf dem Dachboden aufbewahrt werden (Sokolowa);

9. zu Hause aufbewahrt werden:

a. in einer Schachtel (Karjalainen, Lehtisalo, Starzew);

b. aufgehängt werden (Prytkowa);

c. in der Vorderecke des Hauses (Beljawski, Sujew, Karjalainen, Lehtisalo, Mitusowa, Rudenko, Sokolowa, Chomitsch, Schuchow, Eirie);

10. vererbt werden:

a. in weiblicher Linie (Lehtisalo, Sokolowa, Starzew, Tschernezow);

b. in männlicher Linie (Tschernezow).

In älteren Quellen sprachen die Autoren davon, dass die Totenabbilder von den Witwen nach dem Tod ihrer Männer hergestellt wurden (Nowitzki, Georgi, Gondatti). Nach dem Vorstellungsschema von der Seele bei den Obugriern zu urteilen, war der Brauch, Abbild-Totenseelenbehausungen anzufertigen, früher für alle unumgänglich und verbindlich. Fälle, wo der Aufbewahrungsort von zoomorphen (Tschernezow, Starkow) und anthropomorphen (Rudenko) Totenabbildern einer genealogischen Gruppe oder Familie gefunden wurde, sprechen auch dafür. Abbilder wurden nach dem Tod jedes Menschen hergestellt, aber man verhielt sich unterschiedlich zu ihnen. Die Aufbewahrungsmethoden nach Ablauf der Frist der Verwahrung im Hause hingen von der Rolle ab, die der Verstorbene in seinem Leben spielte. Die Totenabbilder von gewöhnlichen, sich durch nichts auszeichnenden Menschen, von Kindern (die schon Zähne hatten; nach Karjalainen, die schon einen Knoten knüpfen konnten, was ein Merkmal für die vorhandene Seele darstellt; Karjalainen 1921, 143), wurden in den Wald getragen und dort vergraben oder einfach weggeworfen. An anderen Orten wurden sie zusammen mit dem Verstorbenen beerdigt (in seinem Grab, im Grabaufbau, 
oder einfach auf dem Friedhof). In einigen Fällen wurden sie an einen Baum gehängt oder mit besonderen Ritualen verbrannt. Es ist möglich, dass die Methoden der Aufbewahrung des Totenabbildes nach Ablauf der Verwahrungsfrist im Hause mit dem Beerdigungsverfahren für die Verstorbenen bei den unterschiedlichen Gruppen der Vorfahren der Obugrier zusammenhängen, und zwar mit der Verbrennung, dem Aufhängen an einem Baum, der Beerdigung im Haus und auf dem Friedhof (Tschernezow 1959, 156). Die vererbten Totenabbilder wurden mit dem letzten Familienangehörigen begraben, falls keine Erben da waren.

Es sind Fälle bekannt, dass die Totenabbilder in speziellen Grabhäuschen aufbewahrt wurden, wobei manchmal die Abbilder der ganzen Familie in ein solches Grabhäuschen hineingelegt wurden (Rudenko). In allen diesen Fällen, bis auf einen von S. I. Rudenko beschriebenen, ist jedoch nicht geklärt, ob in den Grabhäuschen die Abbilder von Menschen aufbewahrt wurden, die eines natürlichen Todes gestorben oder tragisch ums Leben gekommen waren, wie sich in dem von mir beschriebenen Fall am Fluss Synja herausgestellt hatte (Bartenjew, Beketow, Kowalski, Finsch und Brem). Der Brauch, wo von jemandem, der eines gewaltsamen Todes gestorben ist, ein zweites Abbild angefertigt wird, wurde wahrscheinlich nicht nur am Fluss Synja, sondern auch bei anderen Gruppen von Chanten und Mansen befolgt. Bei den nördlichen Chanten und Mansen werden ausser songüt-hot, d. h. den Bauten zur Aufbewahrung der normalen Totenabbilder songüt, die Bauten ura-lobas, üra-xôt und xôt-üra erwähnt. Sie sind als Bauten, in denen "Kultgegenstände" aufbewahrt werden, bekannt geworden (SME, Photothek, Nr. 1706-98, 105-107; Sokolowa 1963, 225; Iwanow 1970, 37). Es besteht offensichtlich eine Ahnlichkeit in den Bezeichnungen der Grabhäuschen für "Kultgegenstände" und des von mir beschriebenen Grabhäuschens für die Aufbewahrung des Abbildes eines Menschen, der eines gewaltsamen Todes gestorben ist, üra, am Fluss Synja. Möglicherweise bestand zwischen ihnen auch eine funktionelle Gleichheit.

Schliesslich wurde ein Teil der Totenabbilder auf Dachböden, Dachbalken oder auf Regalen in der Vorderecke des Hauses aufbewahrt. Das waren Abbilder von verstorbenen Schamanen, von alten und geachteten Menschen, den "berühmten und reichen", unter diesen waren auch Frauen. Meine Funde zeigen, dass solche Abbilder bei den Mansen vom Fluss Ljapin 
die Abbilder von verstorbenen, aber in Ehren stehenden Ahnen darstellen. So war es auch bei den Chanten. Von den neun mir zu Gesicht gekommenen Totenabbildern an den Flüssen Synja und Kunowat wurden sechs nach Ablauf der Frist ihrer Aufbewahrung im Hause am Lieblingsplatz des Verstorbenen weiterhin zu Hause in der Vorderecke, in einer Truhe, manchmal zusammen mit den Schutzgeistern der Familie, aufbewahrt. Ausserdem wurden zwölf von vierzehn Totenabbildern, die ich in alten verfallenen Häusern fand, ständig zu Hause, auf dem Dachboden oder in der Vorderecke des Hauses aufbewahrt. Die Aufbewahrung der Totenabbilder in der Vorderecke des Hauses zusammen mit den Abbildern der Schutzgeister der Familie zeugt in der Regel davon, dass diese Abbilder mit der Zeit selbst als Ahnenbeschützer verehrt wurden. Meistens handelt es sich dabei um Abbilder von Schamanen und alten geachteten Menschen. Möglicherweise schrieb gerade W. F. Sujew darüber: "... Idole ... fertigen sie nicht nur nach den Göttern an, sondern nach den verstorbenen, vormals gepriesenen Wahrsagern oder Reichen oder durch gewisse besondere Taten berühmt Gewordenen, stellen sie als Andenken auf und bitten einen jeden jeweils um das, wofür er ihrer Meinung nach zuständig ist und sie nehmen solche als ihre Beschützer" (Sujew 1947, 40-41). Diese Angaben sprechen für einen entwickelten Ahnenkult bei den Chanten und Mansen. Ausserdem entstand aus diesein Ahnenkult der Kult der Schutzgeister des Hauses oder der Familie (Munkácsi 1905).

Die Totenabbilder werden bei Chanten, die unter den Einfluss von Nenzen geraten sind, als siderjang und niterma, bei den nördlichen Chanten als ittarma, sonat, lon songüt, క̌onat, is-xor, bei den nördlichen Mansen als moxar, itarma, aut akanj, perk njadü mut, bei den Chanten vom Mittleren Ob als ākán bezeichnet. Das zweite Abbild eines tragisch umgekornmenen Menschen heisst üra. Der Begriff is-xor (Karjalainen 1921, 143-144) kommt einmal vor, andere kommen öfter vor. Der Begriff äkán bedeutet 'Puppe'. In anderen Fällen weisen die Bezeichnungen der Totenabbilder einen weiteren sakralen Sinn auf (sonat, కonat bedeutet 'Schädel'; so nannte man auch den Verstorbenen, ohne seinen Namen zu sagen. niterma, ittarma, itərma ist die Bezeichnung, die mit der Verehrung der Schamanen zusammenhängt; Tschernezow 1959, 152). Der Begriff perk njadij mut ist wahrscheinlich deskriptiv, wie auch der von Tschernezow angegebene no xal warim ut (Tschernezow 1959, 152). Der vorhandene nichtsakrale Begriff, der das Totenabbild bei den 
Chanten vom Mittleren Ob bezeichnet, spricht noch einmal vom Aussterben des Brauches, Totenabbilder anzufertigen. Teilweise hatte sich das auch bei den Mansen so zugetragen, wovon S. I. Rudenko berichtete (Rudenko 1972, 51-52).

Inwieweit war der Brauch, Totenabbilder herzustellen, bei den verschiedenen Gruppen der Chanten und Mansen verbreitet? Die Mehrzahl der Autoren beschreibt ihn bei der nördlichen Gruppe der Obugrier: am Unteren Ob (Andrejew, Bartenjew, Beketow, Beljawski, Sujew, Karjalainen, Castrén, Kowalski, Lehtisalo, Pallas, Podrewski, Prytkowa, Rosljakow, Rudenko, Sokolowa, Finsch und Brem, Tschernezow, Schawrow und Eirie), am Kazym (Karjalainen, Prytkowa, Tschernezow, Schuchow), an der nördlichen Soswa mit Ljapin (Gondatti, Rudenko, Sokolowa, Tschernezow).

Die Berichte einzelner Autoren sprechen jedoch davon, dass dieser Brauch auch bei den südlichen (Nowitzki, Patkanow) sowie bei den östlichen (Karjalainen, Mitusowa, Sommje, Starzew) Chanten bekannt war. G. I. Pelich berichtet, dass die Chanten vom Fluss Wach Totenabbilder herstellten (Pelich 1972, 283). Sie beschrieb das Wahrsagen durch eine Chantenfrau vom Wasjugan, wobei eine anthropomorphe Figur verwendet wurde, die aus einem Span angefertigt war und menschliches Haar am Kopf hatte, was eventuell seinen Ursprung in dem Brauch hatte, ein derartiges Totenabbild herzustellen (Pelich 1982, 282).

Mit Ausnahme einiger regionaler Unterschiede ähneln sich die Begräbnisbräuche der Obugrier (Sokolowa 1980). Die nördlichen Chanten und Mansen haben am längsten die archaischen Elemente ihrer Kultur aufrechterhalten, darunter auch die religiösen Vorstellungen, Kulte und Bräuche. Die Chanten aus den östlichen und besonders südlichen Regionen, die südlichen und westlichen Mansen wurden schon früher und intensiver zum Christentum bekehrt, und manche Gruppen gerieten auch unter türkischen Einfluss. Deshalb ist es kein Zufall, dass man auf den Friedhöfen bei den östlichen und südlichen Chanten christliche Kreuze auf den Gräbern antrifft, im Norden findet man sie dagegen nicht vor. Gerade am Unterlauf des Ob blieb noch lange (bis Anfang des 19. Jahrhunderts) die Bevölkerung ungetauft (Chanten und Nenzen). Dadurch wird auch einerseits die anhaltende Befolgung der archaischen Bräuche und Sitten im Norden der Region erklärt, darunter auch des von mir beschriebenen Brauches, Totenabbilder herzustellen, sowie 
andererseits sein Aussterben im Süden und Osten des Siedlungsgebietes der Chanten und Mansen.

Diese wenn auch lückenhaften Angaben zeugen davon, dass der Brauch in der Vergangenheit bei allen Gruppen der Obugrier bekannt war. Noch mehr überzeugt uns davon die Verbreitung eines solchen Brauches unter anderen Völkern, darunter auch den mit den Obugriern benachbarten.

Die engsten Analogien zum Material der Obugrier, das die nach dem Tod eines Menschen hergestellten Totenabbilder betrifft, findet man bei den Nenzen und Selkupen. T. V. Lehtisalo deutet direkt an, dass dieser Brauch nur bei den Nenzen vom Ob bekannt war, diese wiederum hätten ihn bei den Chanten entlehnt. Seiner Meinung nach besteht der Unterschied der Abbilder niterma und siderjang darin, dass ersteres nach dem Tod eines alten Menschen (danach verwandelt es sich in $x ә \times \partial$, d. h. in einen Familiengeist und wird zusammen mit anderen xaxa zu Hause aufbewahrt) und letzteres nach dem Tod eines jungen Menschen angefertigt wurde (es verwandelt sich in xaxa und wird auf dem Friedhof begraben). Aber er deutet es noch anders: siderjang ist die Bezeichnung für das Totenabbild, währenddessen es drei Jahre lang zu Hause aufbewahrt wird, niterma ist die Bezeichnung für das gleiche Totenabbild, aber erst nach Ablauf der dreijährigen Verwahrungsfrist (so ergibt sich, dass das Totenabbild nach Ablauf der dreijährigen Aufbewahrung im Hause die Funktion eines xəxə übernimmt, aber anders bezeichnet wird).

Nach den Angaben von L. W. Chomitsch wird der Brauch, nach dem das Abbild jitarma anzufertigen ist, ausschliesslich von Nenzen befolgt und es handelt sich um das Abbild eines vor langer Zeit in hohem Alter verstorbenen männlichen oder weiblichen Ahnen; mit siderjang wird das Ahnenabbild bei den Nenzen bezeichnet, die von Chanten abstammen. Nach ihren Angaben wird das Abbild nitarma nur die erste Zeit und siderjang fortwährend, solange es nicht beerdigt wird, mit "Essen" versorgt. Das siderjang wird nach drei Jahren beerdigt. Sie meint, dass der Unterschied zwischen siderjang und gitarma mit dem Einfluss der Chanten auf die Nenzen zusammenhängt (Chomitsch 1971, 243-244). Es ist interessant, dass diese Abbilder wie bei den Mansen in der weiblichen Linie aufbewahrt und vererbt werden (ebenda, 247). Die Angaben beider Forscher stimmen sowohl überein, sind jedoch auch unterschiedlich. Es scheint jedoch, dass die Darstellung von 
Lehtisalo der Wahrheit näher kommt. Offensichtlich ist es notwendig, diese Frage weiter zu untersuchen. W. N. Tschernezow meinte, dass die Bezeichnung ittarma oder itarma für das Totenabbild bei den Chanten und Mansen ihren Ursprung in einem Wort der Nenzen hat und mit dem Schamanentum zusammenhängt (Tschernezow 1959, 152). Dennoch gibt es sowohl in den Herstellungs- als auch Aufbewahrungsmethoden für die Totenabbilder bei den Chanten, Mansen und Nenzen viele Gemeinsamkeiten. Höchstwahrscheinlich handelt es sich hier um einen althergebrachten Brauch, der schon bei den Urbewohnern Westsibiriens in weit zurückliegenden Zeiten, möglicherweise im Neolithikum und in der Bronzezeit, entstanden ist und danach bei verschiedenen Völkern transformiert wurde. Das Untersuchungsmaterial von L. W. Chomitsch weist darauf hin, dass sich dieser Brauch bei den Nenzen vor unseren Augen verändert. Sie entdeckte Abbilder von Ahnen Lebender, die die Rolle der Ahnenbeschützer spielen (Chomitsch 1971, 246). Ein solches Faktum wurde erstmalig festgehalten. Gleichzeitig lässt sich die grosse Annlichkeit der Einzelheiten dieses Brauches und jene in der Terminologie bei Nenzen und nördlichen Chanten aller Wahrscheinlichkeit nach durch ihre enge Nachbarschaft und die gegenseitige Assimilation erklären.

Bei den Selkupen wurde dieser Brauch fast gar nicht erforscht. Wie es scheint, ist er schon seit langem verlorengegangen und wurde nur in Einzelfällen in überlieferter Form aufrechterhalten. Bei ihnen stellte das Totenabbild eine anthropomorphe Miniaturfigur dar, die zu Hause aufbewahrt wurde und nach Ablauf einer bestimmten Frist an einem Baum im Wald aufgehängt oder verbrannt wurde (nicht immer) (Pelich 1972, 73, 86). Leider ist nicht bekannt, wie diese Abbilder hergestellt wurden, jodoch ähneln Aufbewahrungsmethode und endgültiges Schicksal dem, was bei den Chanten und Mansen üblich war.

Die Keten besassen Miniaturtotenabbilder (danol's), die aus speziell angefertigten Kleidungsstücken bestanden, worin sich manchmal eine Stoffrolle oder eine anthropomorphe Figur befand. Das waren die Abbilder von Menschen, die eines gewaltsamen Todes gestorben waren; sie wurden zu Hause zusammen mit den Familiengeistern aufbewahrt. Sie halfen den Verwandten des Verstorbenen bei der Arbeit (Alexejenko 1967, 181-182). B. O. Dolgich berichtet, dass ein dajol's hergestellt wird, sobald jemand seinen verstorbenen Verwandten im Traum gesehen hat. Die Grösse solcher Ab- 
bilder beträgt 23 bis $28 \mathrm{~cm}$ (MAE, Nr. 4919-23-25). Gewisse Abbilder namens ala-albam wurden nicht zur Unterstützung bei der Jagd verwendet. In der Sammlung von B. O. Dolgich gibt es ein Abbild danol's mit einem mit Ornamenten versehenen Kupferplättchen am Kinn (MAE, Nr. 4919-25).

Totenabbilder namens kama-aru-nama wurden von den Bewohnern des Altai hergestellt und zu Hause aufbewahrt. Sie wurden aus Bändern hergestellt. Man war der Meinung, dass der Geist des Verstorbenen am 3. oder 7. Tag nach dem Tod bei den Verwandten erscheint und ein blutsverwandter Geist wird (MAE, A. Anochin 1911, Nr. 1853-13, 16). Die Ewenken vom Fluss Ud fertigten Totenabbilder aus Holz an, die Witwe oder der Witwer legten sie zu sich ins Bett (Solotarjow 1938, 78). Die Ewenken vom Fluss Podkamennaja Tunguska stellten hölzerne Abbilder der toten und lebendigen physiologischen Menschenseele her. Bei der Gedenkfeier wurde ein solches Abbild mit dem Fleisch und Blut eines Opferrentieres "bewirtet" (MAE, 1923, Nr. 4323-111, 112). Im MAE wird ein Totenabbild aufbewahrt, das die Ewenken vom Fluss Bargusin aus einem phosphorisierenden Stück Holz hergestellt haben (MAE, Nr.2216-10). Der Kopf ist länglich oval, die Arme sind in Form von Stummeln ausgebildet, die Taille ist angedeutet und die Füsse sind eingeschnitten. Das Abbild befand sich im Haus neben dem Feuer und es war ein Messer daran angebunden. Später brachte es der Schamane mit dem Rentier weg. Die Tuwinen fertigten ebenfalls Totenabbilder an; am Tag der Beerdigung wurden diese zur Ablenkung der bösen Geister aus dem Haus herausgetragen (mündliche Mitteilung von S. I. Wainstein).

Die Jakuten fertigten früher auch Totenabbilder aus Holz an, diese wurden in einer Baumhölung hinter dem Haus aufbewahrt und in bestimmten Abständen "mit Essen versorgt" (Priklonski 1890). Sie stellten auch Totenabbilder aus Birkenrinde, Ton und anderem Material her (Brawina 1982). Nach dem Tod eines Mädchens fertigten die Eltern ihr Abbild aus der Fessel eines Pferdes oder einer Kuh an und setzten einen silbernen Kopf darauf; das Abbild wurde mit einem Pelzmantel bekleidet, der mit Silberschildchen ausgeschmückt war, und in einem Behälter aus Birkenrinde untergebracht. Es wurde zu Hause oder in einer Baumhöhlung aufbewahrt (Gurwitsch 1980, 98; Karjalainen 1921, 177). Die Mongolen fertigten auch Totenabbilder an, die der Gestalt nachgebildet waren, in der Wohnung aufbewahrt und verehrt wurden (Karjalainen 1921, 177). 
Die Verkörperung von Verstorbenen ist in Gestalt von Abbildern und Seelenbehausungen auch bei den anderen Völkern Sibiriens, des Wolgagebietes, Mittelasiens oder Europas gut bekannt. Bei den Korjaken zum Beispiel nahm sofort jemand den Platz des Verstorbenen in der Wohnung ein. Wenn dieser unbesetzt blieb, wurde aus Gras eine menschliche Figur nachgebildet und am Platz des Verstorbenen plaziert, sonst könnte ein böser Geist diesen Platz einnehmen (Kuschner 1925, 378). Die Tschuktschen schnitten vom Kleid des Verstorbenen ein Stück ab und banden es an die Familienamulette (enaal). In einigen Familien wurden kleine Stücke von Rentier- und Hundefell zusammengenäht, auf den Verstorbenen gelegt und danach wurden diese mit den Familienamuletten aufbewahrt (ebenda, 380).

Bei den Amurvölkern (Nanaizen, Ultschen) fertigte man die Totenabbilder (mugda, fanja 'Seele, wie') aus Holz an und zog die Kleidung darüber. Es wurde angenommen, dass am 7. Tag nach dem Tod eines Menschen seine Seele nach Hause zurückkehrt. Der Schamane flösste sie der hölzernen Figur fanja, panja oder ajami fanjalka ein; ihre Grösse beträgt 17,5 bis $18 \mathrm{~cm}$ (Smoljak 1980, 180, 185; Lipski 1966, 108; SME, D. K. Solowjow, Nr. 1998193-194. 1910). Die hölzerne Skupltur mugda vertrat den Verstorbenen während des Rituals kasatauri, d. h. während die Seele ins Jenseits geleitet wird (grosse Gedenkfeier). Dieses Ritual erfolgte unter Teilnahme des Schamanen einige Jahre nach dem Tod des Menschen. Nach dem Ritual wurde das mugda zusammen mit den Sachen des Verstorbenen verbrannt. In einigen Fällen wurde das mugda mit einem Beil gespalten und weggeworfen, seine Grösse betrug $81 \mathrm{~cm}$ (SME, Nr. 1998-195). Die Totenabbilder fanja, panja und ajami fanjalka wurden im Hause auf einer Schlafbank, auf dem Bett des Verstorbenen aufbewahrt. Man stellte ihnen Essen, Wodka und Tabak hin (SME, L. J. Sternberg 1756-226, 227; MAE, Photothek, E. G. Schneider 1908, Nr. 4700-1261; MAE, A. N. Lipski 1917 bis 1919, Nr.n1535-51,n-1539-162). Im Abbild wurde ein Loch angebracht, in welches die Rauchpfeife gesteckt wurde (MAE, A. N. Lipski, Nr. 5530-67). Die Abbilder namens fanja wurden manchmal aufgehoben und für magische $Z$ wecke bei der Krankenbehandlung verwendet (MAE, Nr. 5530-66).

Die Verkörperung des Verstorbenen in Gestalt seiner Kleidung und Waffe ist bei den Bulgaren, den Bewohnern Bosniens, Montenegros (Karja- 
lainen 1921, 177), bei den Kasachen und Kirgisen und einer ganzen Reihe anderer Völker bekannt (Abramson 1946; Schischlo 1972, 1975).

Eine derartig weite Verbreitung des Brauches, ein Totenabbild herzustellen und aufzubewahren, spricht für seine Altertümlichkeit. Aller Wahrscheinlichkeit nach hängt dieser Brauch mit den altertümlichen Vorstellungen dieser Völker von der Seele und der Möglichkeit ihrer Wiedergeburt zusammen. Die Taschtyker Totenabbilder aus der ersten Hälfte des 1. Jahrtausends $u$. Z. sind die altertümlichsten der durch archäologische Ausgrabungen bekannt gewordenen Totenabbilder (Kyslasow 1960, 101. Der Autor setzt sie "ihrer Bestimmung nach den Totenabbildern der Chanten gleich", S. 102-104, 167). Möglicherweise handelt es sich auch bei jenen anthropomorphen Figuren um Totenabbilder, die während der Ausgrabungen der Andronow-Denkmäler aus der Bronzezeit vom 2. Jahrtausend v. u. Z. in Westsibirien und der Serow-Denkmäler im Baikalgebiet aus der ersten Hälfte des 3. Jahrtausend v. u. Z. aus dem Neolithikum gefunden wurden.

Folglich ist dieser Brauch sehr alt, für viele Völker charakteristisch und er zeichnet sich durch interessante Details aus. Er ist eng mit den Vorstellungen dieser Völker von der Seele verbunden und kann nur in diesem Zusammenhang untersucht werden. Hinsichtlich Entstehung und Entwicklung dieses Brauches bei den verschiedenen Völkern und in seinen Einzelheiten ist noch vieles ungeklärt. Bei der Erforschung der Seelenvorstellungen und der Begräbnisbräuche sollte darauf geachtet werden. 


\section{LITERATUR}

Абрамсон С.М. 1946 "Тул" как пережиток анимизма у киргизов. - В кн.: "Белык С. Е. Малову", Фрунзе. ("Tul" als ein Uberbleibsel des Animismus bei den Kirgisen)

Алексеенко E. А. 1967. Кеты. Л. (Die Keten)

Андреев Г. 1832.0писание Г. Березова и его округа.- "Северная пчела", N" 207. (Beschreibung der Stadt Beresow und ihrer Umgebung)

Бартенев В. В. 1895. Погребальные обычаи обдорских остяков.-"Живая старина", вып. Ш. IV. CПб. (Begräbnisbräuche bei den Obdorsker Ostjaken)

Бекетов Л. 1857. Заметки об инородцах Березовского округа. - "Тобольские губернские ведомости", № 13. (Bemerkungen zu den Fremden des Beresowsker Kreises)

Белявский Ф. 1833. Поездка к Ледовитому морю. М. (Reise zum Eismeer)

Бравина Р. И. 1982. Представления якутов о духе юёр. - Вестник ЛГУ, серия: история, язык, литература, вып. 3, N 8 . stellungen der Jakuten über den Geist Jujör)

Высоцкий Н. Ф. 1908. Несколько слов о погребальных обычаях вогул. Известия общества археологии, истории и этнографии при Казанском университете, т. XXIV, вып. 3, Казань. (Einige Worte über die Begräbnisbräuche bei den Wogulen)

Георги И. Г. 1776. Описание всех в Российском государстве обитающих народов , 4. I, СПб. (Beschreibung aller im Russischen Reich ansässigen Völker)

Глушков И. 1900.Чердынские вогулы. - Этнографческое обозрение, т. XV , вып. 2, СПб. (Tscherdynsker Wogulen)

Гондатти Н. 1888. Следы языческих верований у маньзов. - Труды этнографического отдела императорского общества любителей естествознания, антропологии и этнографии при Московском университете, Кн. VII, M. (Spuren des Heidenglaubens bei den Mansen)

Гурвич И.С. 1980. Якуты. Похоронная обрядность. - В кн.: "Семейная обрядность". M. (Jakuten. Begräbnisbrauchtum)

Золотарев А. М. 1938. Новые данные о тунгусах и ламутах в XVIII в. - Историк-марксист, $\mathbb{N}^{\circ} 2$. (Neue Angaben über die Tungusen und Lamuten im 18. Jahrhundert)

Зуев В. Ф. 1947. Описание живущих в Сибирской губернии в Березовском уезде иноверческих народов остяков и самоедов. - В кн.: Материалы по этнографии Сибири XVIII века (1771-1772). Труды Института этнографии, новая серия, т. V, M. (Beschreibung der Bewohner des Gouvernements Sibirien im Beresowsker Landkreis und der andersgläubigen Völker der Ostjaken und Samojeden)

Иванов С. В. 1970. Скульптура народов Севера Сибири XIX - первой половины XX в. Л. (Die Bildhauerei der Völker des Nordens Sibiriens im 19. Jahrhundert und in der ersten Hälfte des 20. Jahrhunderts)

Kannisto A. 1958. Materialien zur Mythologie der Wogulen. - Mémoires de la Société Finno-Ougrienne 113. Helsinki.

Karjalainen K. F. 1921. Die Religion der Jugra-Völker. Bd. I. - FF Communications 8: 40 .

Кастрен М. А. 1860. Путешествие по Лапландии, Северной России и Сибири (1838-1844, 1845-1849). - Собрание старых и новых путеше- 
ствий, 4. II, M. Russland und Sibirien)

(Eine Reise durch Lappland, das nördliche Képes Gy. 1972. Napfél és Éjfél. Finnugor rokonaink népköltészete. Budapest.

Ковальский М. 1853. Северный Урап и береговой хребет Пай-хой. Труды экспедиции Русского географического общество, т. I. спб. (Der nördliche Ural und der Ufergebirgsrücken Pai-Choi)

Кушнер П. (Кнышев). 1925. Первобытное и родовое общества. М. (Urund Gentilgesellschaft)

Кызласов Л. Р. 1960. Таштыкская эпоха в истории Хакасско-Минусин ской котловины. M. (Die Taschtyker Epoche in der Geschichte des Chakassko-Minusinsker Talkessels)

Липский А. Н. 1966. К вопросу об использовании этнографии для интерпретачии археологических материалов. - Советская этнография, $N^{2}$ I. (Zur Frage der Anwendung der Ethnographie bei der Interpretation archäologischer Materialien)

Любарских П. 1792. Краткое известие о пермских, чердынских вогуличах. - Российский магазин, ч. I. СПб. (Ein kurzer Bericht über die Wogulen aus Perm und Tscherdyn)

Мельников C. 1852. Сведения о мансах, кочующих в Березовском уезде. - Вестник Русского географического общества, т.V, СПб. (Bericht über die im Beresowsker Landkreis nomadisierenden Mansen)

Munkácsi B. 1905. Seelenglaube und Totenkult der Wogulen. - Keleti Szemle 6. Budapest.

Новицкий Г. 1884. Краткое описание о народе остяцком. СПб. (Eine kurze Beschreibung des Volkes der Ostjaken)

Паллас П. С. 1778. Путешествие по разным провинциям Российской империи. - Част III, половина I, СПб. (Eine Reise durch verschiedene Provinzen des Russischen Reiches)

Patkanov S. 1897. Die Irtysch-Ostjaken und ihre Volkspoesie. B. 1. St.-Ptb.

Пелих Г. И. 1972. Происхождение селькупов. Томск. (Die Herkunft der Selkupen)

Подревский Н. 1895. Поездка на Северный Урал летом 1892 года. М. (Reise zum nördlichen Ural im Sommer 1892)

Прыклонский В. Л. 1890. Якутские народные роверья и сказки. -- Живая старина, вып П.(Volksglaube und Volksmärchen aus Jakutien)

Прыткова Н. Ф. 1971. Один из источников изучения одежды народов Сибири. - В кн.: Религиозные представления и обяды народов Сибири в XIX-начале XX века. Сборник МАЭ. XXVII, Л. (Eine der Quellen der Untersuchung der Kleidung der Völker Sibiriens)

Rudenko S. I. 1972. Die Ugrier und die Nenzen am unteren Ob. - Acta Ethnographica 21.

Росляков И. П. 1896. Похоронный обряд остяков. - Ежегодник Тобольского губернского музея, вып. V, Тобольск. (Begräbnisbrauchtum bei den Ostjaken)

Смоляк А. В. 1980. Нанайцы. Ульчи. Похоронная обрядность. - В кн: Семейная обрядность. (Nanaizen, Ultschen und Begräbnisbrauchtum)

Соколова 3. П. 1971. Пережитки религиозных верований у обских угров. - В кн.: Религиозные представления и обряды народов Сибири в XIX-начале XX века. Сборник МАЭ, XXVII, л. (Uberbleibsel religiösen Glaubens bei den Obugriern) 
Соколова 3. П. 1972. Ханты рек Сыня и Куноват. - В кн.: Материалы по этнографии Сибири. Томск. (Die Chanten von Synja und Kunowat)

Соколова 3. П. 1974. ОБ одном традиционном обычае погребального цикла сынских хантов. - В кн.: Новое в этнографических и антропологических исследованиях. М. (Uber einen traditionellen Brauch im Begräbniszyklus der Chanten an der Synja)

Соколова 3. П. 1975а. Находки в Шишингах (Культ лягушки и угорская проблема). - Советская этнография, № 6. (Funde in Schischingi (Der Kult des Frosches und das Ugorsker Problem))

Соколова 3. П. 19756. Новые данные о погребальном обряде северных хантов. - В кн.: Полевые исследования Института Этнографии 1974. M. (Neue Angaben über das Begräbnisbrauchtum der nördlichen Chanten)

Соколова 3. П. 1975в. Наследственные, или предковые, имена у обских угров и связанные с ними обычаи. - Советская этнография, № 5. Vererbte oder von den Ahnen erworbene Namen bei den Obugriern und damit verbundene Bräuche)

Соколова 3. П. 1976а. Страна 10гория. M. (Das Land Jugorien)

Sokolowa S. 1982. Das Land Jugorien. Verlag Progress Moskau. VEB F.A. Brockhaus Verlag Leipzig.

Соколова 3. П. 1978. О некоторых погребальных обычаях северных хантов и манси. - В кн.: Этнография народов Алтая и Западной Сибири. Новосибирск.

Chanten und Mansen)

Соколова 3. П. 1980. Ханты и манси. Похоронная обрядность. - В Кн.: Семейная обрядность. M. (Chanten und Mansen)

Соколова 3. П. 1982. Путешествие в 10гру. M. (Reise nach Jugra)

Sokolowa Z. P. 1976. Untersuchung der religiösen Vorstellungen der Hanti am Unterlauf des Ob. - Acta Ethnographica 24(3-4). Budapest.

Сорокин Н. 1873. Путешествие к вогулам. - Труды общества естествоиспитателей при императорском Казанском университете, т. III, $N^{0} 4$, Казан. (Reise zu den Wogulen)

Старцев Г. 1928. Остяки. M. (Die Ostjaken)

Финш 0. и Брэм А. 1882. Путешествие в Западную Сибирь. М. (Reise nach Westsibirien)

Хомич Л. В. 1971. О некоторых предметах культа надымских ненцев. В кн.: Религиозные представления и обряды народов Сибири в ХІХначале XX века. Сборник MAЭ, XXVII. Л. (Über einige Kultgegenstände bei den Nenzen vom Nadym)

Старков В. Ф. 1973. Новые находки плоского литья в Нижнем Приобье. - В кн.: Проблемы археологии урала и Сибири. М. (Neue Flachguss-Funde am Unterlauf des $\mathrm{Ob}$ )

Чернецов В. Н. 1941. Очерк этногенеза обских югров. - Краткие сообщения института истории материальной культуры, IX. (Abhandlung über die Ethnogenese der Obugrier)

Чернецов В. Н. 1953. Усть-Полуйское время в Приобье. - Материалы и исследования по археологии ССCP, N 35. (Die Zeit des Ust-Poluj im Obgebiet)

Чернецов В. Н. 1959. Представления о душе у обских угров. - В кн.: Исследования и материалы по вопросам первобытных религиозных верований. Труды Института этнографии, новая серия, т. 51, М. (Die Vorstellungen von der Seele bei den Obugriern) 
Чернецов В. Н. 1971. Наскальные изображения Урала. - Свод археологических источников, 84-12 (2), М. (Felszeichnungen im Ural Zusammenstellung der archäologischen Quellen)

Шавров В. Н. 1871. Краткие записки о жителях Березовского уезда. - Чтения в обществе истории и древностей российских, кн. 2, Спб. (Kurze Notizen über die Bewohner des Beresowsker Landkreises)

Шишло Б. П. 1972. Культ предков и заместители умерших. - Вестник Ленинградского государственного университета, № 8 . (Der Ahnenkult und die Verkörperung der Verstorbenen)

Шишло Б. П. 1975. Среднеазиатский тул и его сибирские параллели.

- В кн.: Домусульманские верования и обряды в Средней Азии. М. (Das mittelasiatische "Tul" und seine sibirischen Parallelen)

Шухов И. Н. 1914. Река Шучья. - Ежегодник Тобольского губернского музея, вып. XXII. (Der Fluss Schutschja)

Эйрие Ж. Б. Б. 1839. Живописное путешествие по Азии. М. (Eine malerische Reise durch Asien)

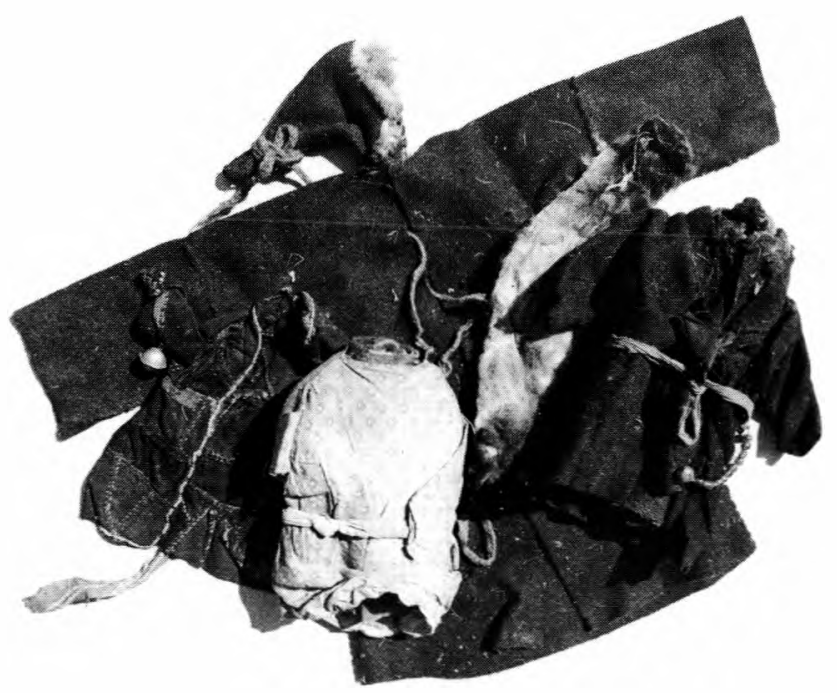

Abb. 1 


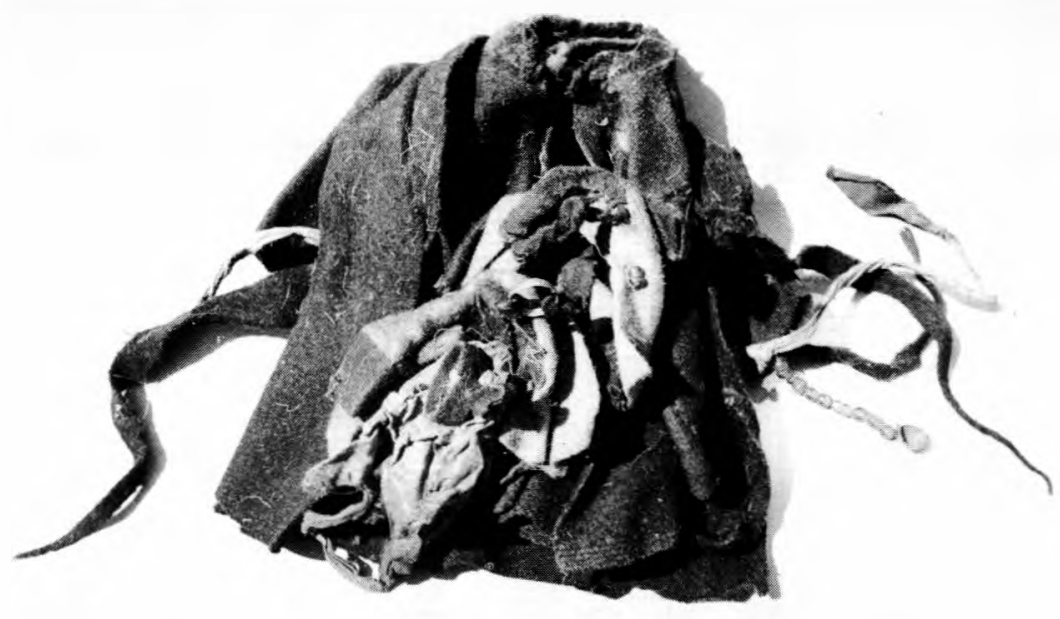

Abb. 2

Abb. 3

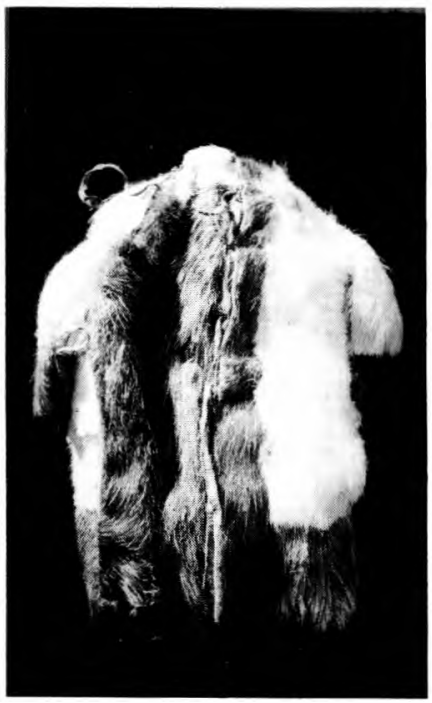




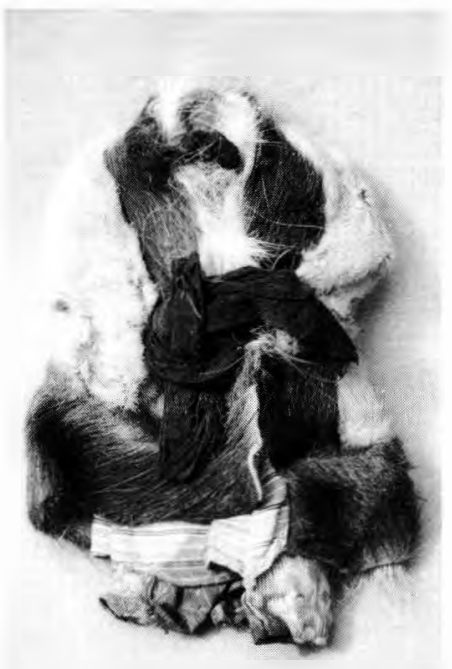

Abb. 4
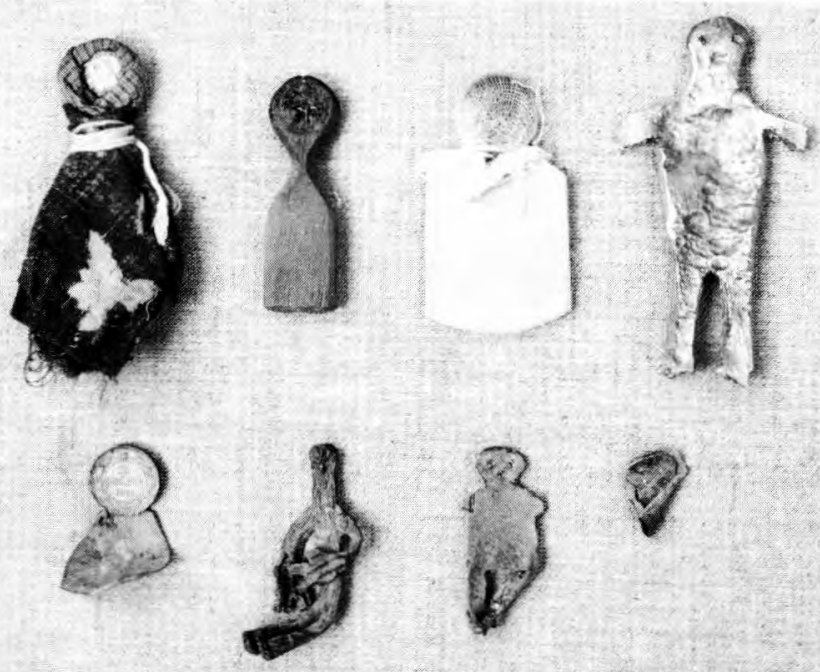

Abb. 5 


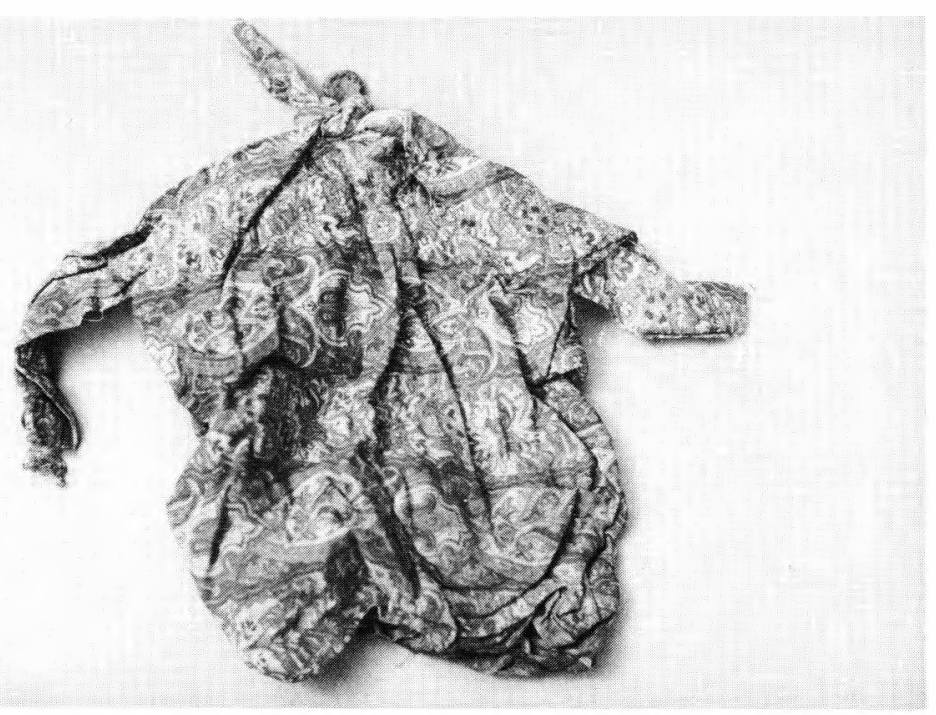

Abb. 6

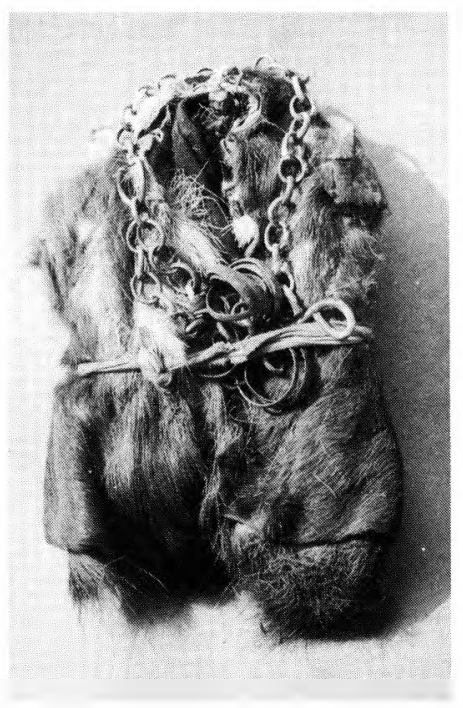

Abb. 7 
Abb. 8

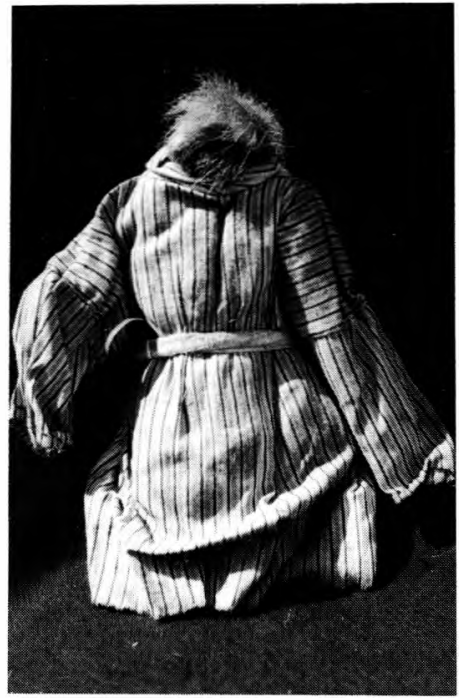

Abb. 9

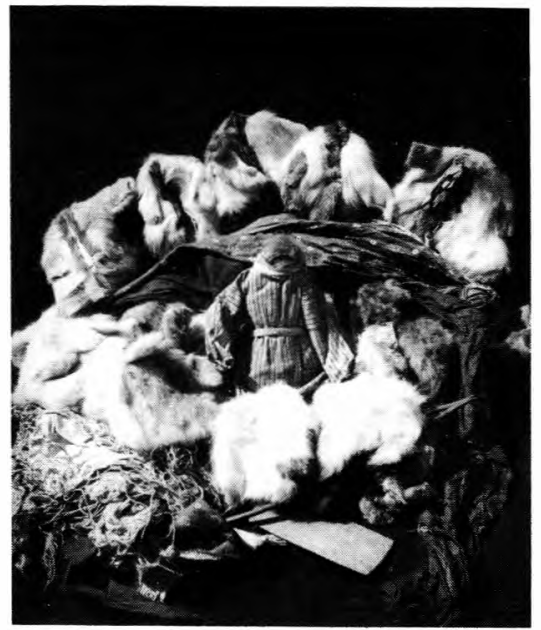


Abb. 10
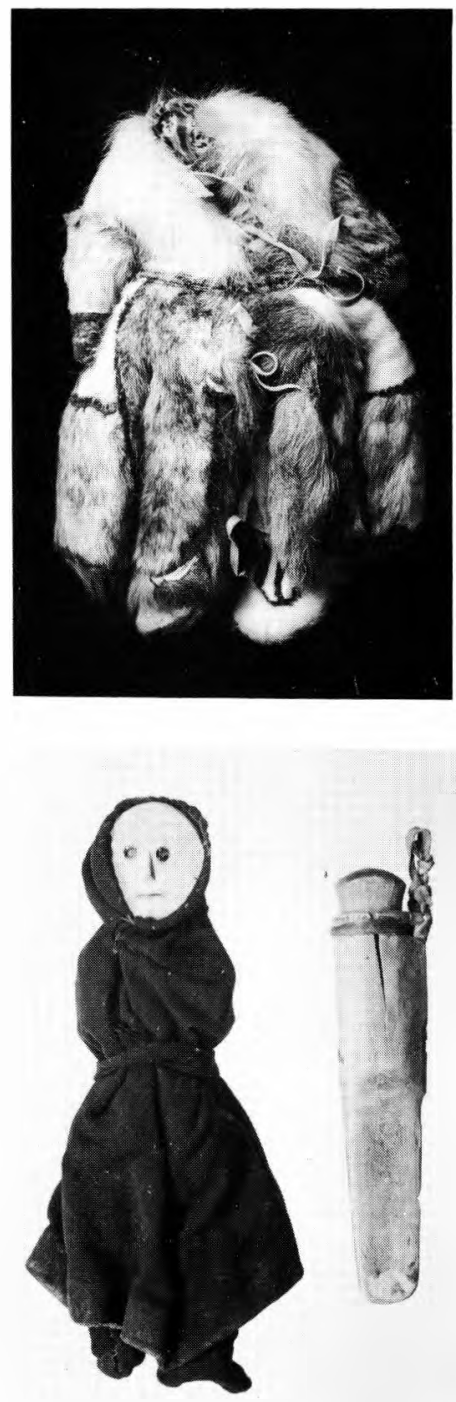

Abb. 11 


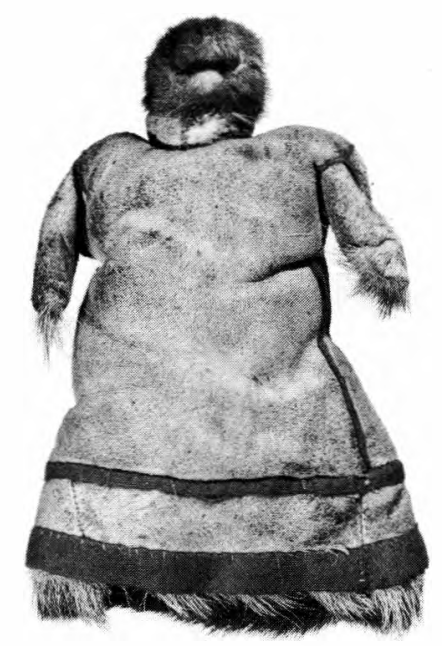

Abb. 12
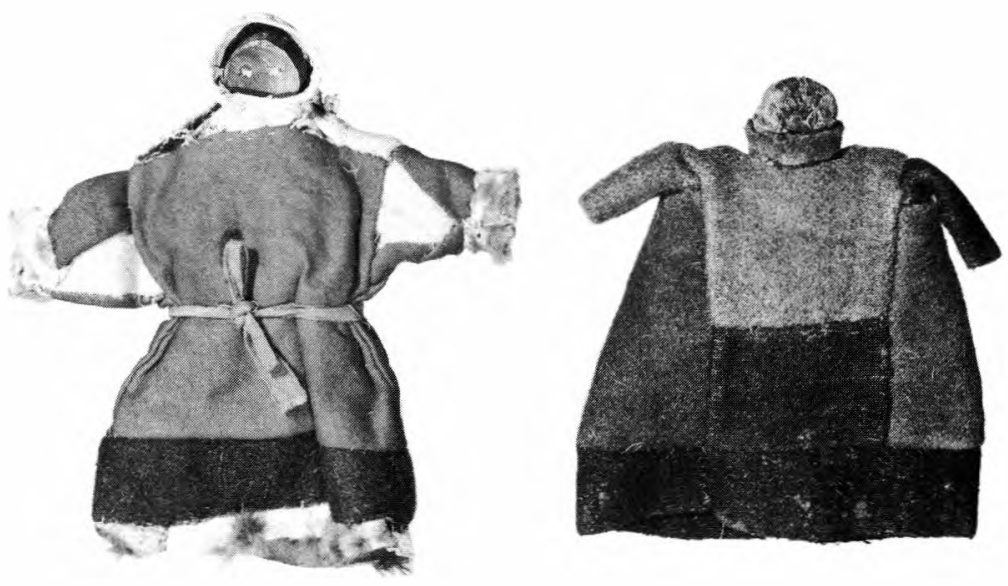

Abb. 13 


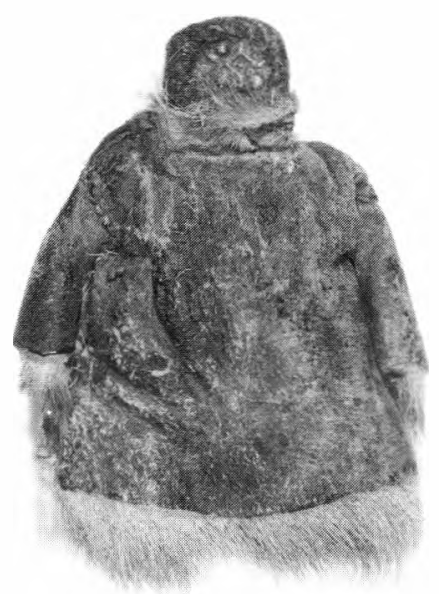

Abb. 14

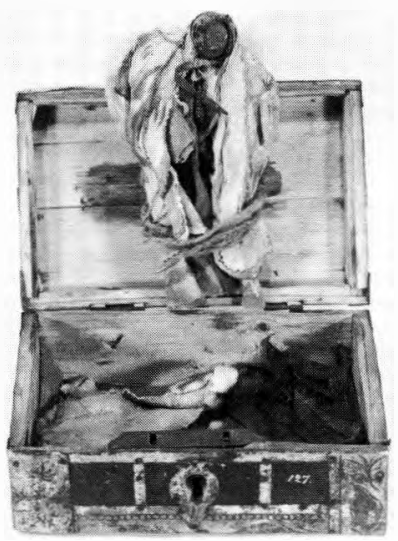

Abb. 15 


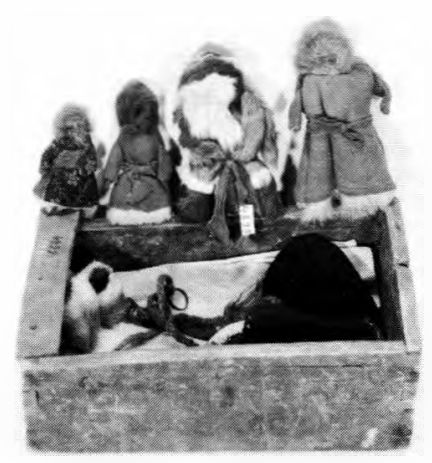

Abb. 16

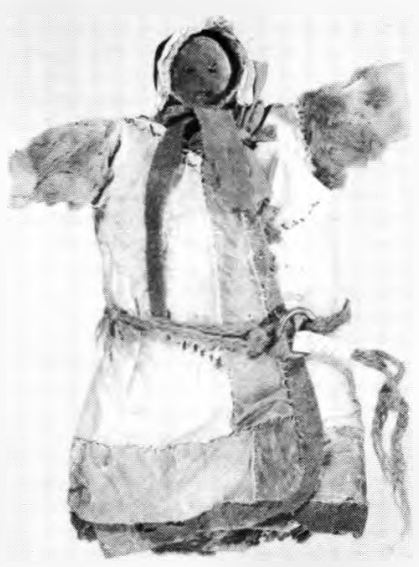

Abb. 17 


\section{VERZEICHNIS DER ABBILDUNGEN}

Abb. 1. Abbilder von verstorbenen Chanten (Männer und Frauen) mit den ihnen dargebrachten Gaben aus der Siedlung Nimwoschgort (Fluss Synja). Foto der Autorin.

Abb. 2. Abbild einer verstorbenen Frau aus der Siedlung Nimwoschgort, aus Kleidungsstücken bestehend, die untereinander durch Bänder verbunden sind (auf Abb. 1 ganz rechts). Foto der Autorin.

Abb. 3. Frauen-Pelzmantel-Sach, eine verstorbene Frau darstellend (Siedlung Lopchari, Fluss Kunowat). Foto der Autorin.

Abb. 4. Abbild einer verstorbenen Chantenfrau mit einem Gesicht aus einer Münze aus der Siedlung Schischingi (Fluss Ob). Foto der Autorin.

Abb. 5. Körper der Totenabbilder der Chanten (von links nach rechts): a - aus der Siedlung Schischingi (s. Abb. 4); b - aus der Siedlung Owolyngort, Fluss Synja; c - aus der Siedlung Schischingi; $d$ - aus der Siedlung Nimwoschgort (auf Abb. 1 links); e - aus der Siedlung Schischingi; $\mathrm{f}$ - aus der Siedlung Gorbungort, Fluss Synja; g - aus der Siedlung Wytwoschgort, Fluss Synja; h - aus der Siedlung Schischingi (a - Münze und Stoff, b, c - Holz, d, f, g - Metall, e - Metall und Münze). Foto der Autorin.

Abb. 6. Totenabbild eines Chanten aus der Siedlung Gorbungort. Foto der Autorin.

Abb. 7. Totenabbild einer Chantenfrau aus der Siedlung Gorbungort (s. Abb. 5f). Foto der Autorin.

Abb. 8. Totenabbild eines Chanten aus der Siedlung Wytwoschgort (s. Abb. 5g). Foto der Autorin.

Abb. 9. Totenabbild eines Chanten aus der Siedlung Wytwoschgort mit den ihm dargebrachten Gaben. Foto der Autorin.

Abb. 10. Ura - das Abbild einer ertrunkenen Frau (Siedlung Owgort, Fluss Synja). Foto der Autorin.

Abb. 11. Totenabbild eines Chanten mit einem Messer (Holz, Augen aus einer Glasperle; SK V T. V. Lehtisalo, Nr. 4899-129).

Abb. 12. Totenabbild eines Chanten vom Fluss Poluj (Holz; SKM, T. V. Lehtisalo, Nr. 4899-131). 
Abb. 13. Totenabbilder der Chanten aus der Siedlung Wylposlpugol (Holz; SKM, T. V. Lehtisalo, Nr. 4899-151, 149; Nr. 4899-151: Gesicht aus einer Münze).

Abb. 14. Totenabbild eines Chanten aus der Siedlung Wylposlpugol (Gesicht aus einem Zinnschildchen; SKM, T. V. Lehtisalo, Nr. 4899-150).

Abb. 15. Totenabbild einer Nenzenfrau in einer Truhe (Holz; SKM, T. V. Lehtisalo, Nr. 4899-127).

Abb. 16. Kiste mit vier Totenabbildern der Verwandten eines Schamanen aus dem Nenzengeschlecht Tocho, mit den ihnen dargebrachten Gaben (Holz; SKM, T. V. Lehtisalo, Nr. 4899-128).

Abb. 17. Totenabbild einer Nenzenfrau-Schamanin (Holz- SK:M, T. V. Lehtisalo, Nr. 4899-147). 